\title{
LOS REPRESAMIENTOS HIDRÁULICOS PREHISPÁNICOS EN EL FLANCO OCCIDENTAL DE LA CORDILLERA NEGRA, ÁNCASH, PERÚ
}

\author{
PREHISPANIC HYDRAULIC DAMMING ON THE WESTERN SIDE OF THE \\ CORDILLERA NEGRA, ANCASH, PERÚ
}

\author{
Jesús Maza $a^{1,2}$ y Andy Combey $y^{2,3}$
}

\begin{abstract}
Este articulo presenta el estudio de las estructuras hidráulicas conocidas como represas, ubicadas en la subcuenca del Río Jimbe en la cabecera del Valle de Nepeña (Áncash), a partir de prospecciones sistemáticas en el área referida. La investigación permitió registrar 14 represamientos prehispánicos dentro de tres distintas quebradas. El análisis morfológico y espacial de estos sistemas hidráulicos sugiere un manejo diferenciado del agua en el flanco occidental de la Cordillera Negra y aboga por una reevaluación de las estrategias de explotación del territorio por los grupos serranos durante la época prehispánica tardía.
\end{abstract}

Palabras claves: represas, Cordillera Negra, pastoralismo, riego, prehispánico.

This article presents a study of the hydraulic structures -known as dams- in the Jimbe River sub-basin of the headwaters of the Nepeña Valley (Ancash), based on systematic surveys carried out in that sector. This study allowed for recording 14 pre-Hispanic dams in three different sub-valleys. The morphological and spatial analysis of these hydraulic systems suggests differentiated management of water on the western side of the Cordillera Negra and provides evidence for a reassessment of land use strategies set up by Sierra people during the late pre-Hispanic Period.

Key words: Dams, Cordillera Negra, pastoralism, irrigation, pre-Hispanic.

El manejo del agua se constituye como un tema central para el entendimiento de la organización socioeconómica de los grupos humanos que habitaron el paisaje andino (Carrión Cachot 2005 [1955]; Consejo Andino 1988; Gelles 2002; Gerbrandy y Hoogendam 1998; Kosok 1965). Los grupos humanos prehispánicos asentados en las estribaciones occidentales de los Andes se desarrollaron en medios naturales que solían carecer de recursos hídricos estables.

La Cordillera Negra, sistema orográfico regional que corre paralelo a la costa ancashina a una distancia promedio de $60 \mathrm{~km}$, sin glaciares y fuentes de agua permanente, representa una región natural peculiar, que permite conocer los desafíos que deben enfrentar las poblaciones en ecosistemas de altura. Para proveerse eficientemente del agua, las sociedades locales desarrollaron varios mecanismos.

La evidencia encontrada en las distintas fuentes sugiere que las represas hidráulicas, conocidas como qochas en el mundo andino (Vivanco 2015), o lagunas en el ámbito geográfico (Pulgar Vidal 1998), podrían reflejar las estrategias de subsistencia de las sociedades que las construyeron y que, en consecuencia, se vieron beneficiados por el funcionamiento de estas obras hidráulicas. Uno de los temas abordados aun incipientemente desde el punto de vista arqueológico es el referido a las estructuras hidráulicas conocidas como represas.

En ese sentido, el extenso sistema hidráulico Huiru Catac $^{1}$, ubicado en el valle alto de Jimbe (Maza 2018b, 2018c), y sus numerosas lagunas represadas (Combey 2018b; Gambini 1975; Llosa 2008) en épocas pasadas, destacan por su cantidad de inversión hidráulica y brindan un escenario interesante para evaluar el papel de estas tecnologías en el mundo andino prehispánico.

La presente investigación presenta, de manera preliminar los resultados de las investigaciones en la parte septentrional del valle alto de Nepeña, e intenta aproximarse a la comprensión de estas estructuras hidráulicas.

\footnotetext{
${ }^{1}$ Universidad Nacional Mayor de San Marcos, Lima, Perú. jesusbrave@ hotmail.com

${ }^{2}$ Círculo Cultural Cordillera Negra, Lima, Perú.

${ }^{3}$ Université Grenoble Alpes, CNRS (Centre National de la Recherche Scientifique), IRD (Institut de Recherche pour le Développement), IFSTTAR (Institut français des sciences et technologies des transports, de l'aménagement et des réseaux), ISTerre (Institut des Sciences de la Terre), Grenoble, France. andy.combey@univ-grenoble-alpes.fr
} 


\section{Características Geográficas y Medioambientales}

La zona de investigación comprende las partes altas del distrito de Cáceres del Perú (provincia de Santa, Áncash), en el flanco occidental de la sección norte de la Cordillera Negra. Las características principales de este medio natural corresponden a las descripciones generales otorgadas para la región Suni y Puna de la región andina (Pulgar Vidal 1998), aunque también comparte características que corresponden a la puna de los Andes centrales (Custred 1977).

La cuenca del Río Jimbe se origina por la confluencia de los numerosos cursos de agua que descienden del flanco occidental de la Cordillera Negra, generalmente siguiendo una orientación suroeste. Las quebradas de mayor importancia se caracterizan por tener cursos de agua que se originan usualmente en las lagunas situadas en sus cabeceras. Muchas de estas lagunas naturales se encuentran actualmente represadas con materiales modernos, aunque las bases o cimientos de las mismas correspondan posiblemente a represamientos prehispánicos, posiblemente tardíos.

Según Gambini (1975), el Río Jimbe nace de la Laguna Huampucayán y sigue su curso río abajo para unirse con otras quebradas y riachuelos. Los de mayor importancia lo componen los tributarios que bajan de las quebradas (de norte a sur) de Lampanín, Capado, Huirí, Huampucayán, Mátar y Cosma (Figura 1).
Geológicamente, la zona de estudio está compuesta por formaciones terciarias de Calipuy volcánico alternadas con sustratos geológicos del Cretácico (formaciones Santa-Carhuaz), así como un gran componente de granodiorita tonalita para el área superior de la Quebrada Capado especialmente ${ }^{2}$. Esas rocas, puntualmente fracturadas como los depósitos fluvio-glaciares ubicados en los fondos de las quebradas, constituyen acuíferos de "productividad elevada" (Sistema de Información Geográfica del GEOCATMIN) ${ }^{3}$.

En el marco de esta investigación se han prospectado las cabeceras de tres quebradas principales (nombradas de norte a sur): Capado, Huampucayán y Mátar. Si bien las tres quebradas comparten similares características geográficas y medioambientales por ubicarse en zonas ecológicas comparables, existen algunas diferencias que debemos tener en cuenta y que señalaremos a continuación.

La primera, la Quebrada Capado, se encuentra en la parte nororiental del distrito y contiene en sus cabeceras abundantes zonas planas que podrían representar probables zonas de pastoreo en la antigüedad ${ }^{4}$ y que podrían denominarse pequeñas mesetas. Asimismo, no se encuentran núcleos poblaciones en sus proximidades, salvo algunas unidades habitacionales temporales (chozas) de pastores provenientes del caserío moderno de Carhuamarca. Según versiones locales, la cabecera

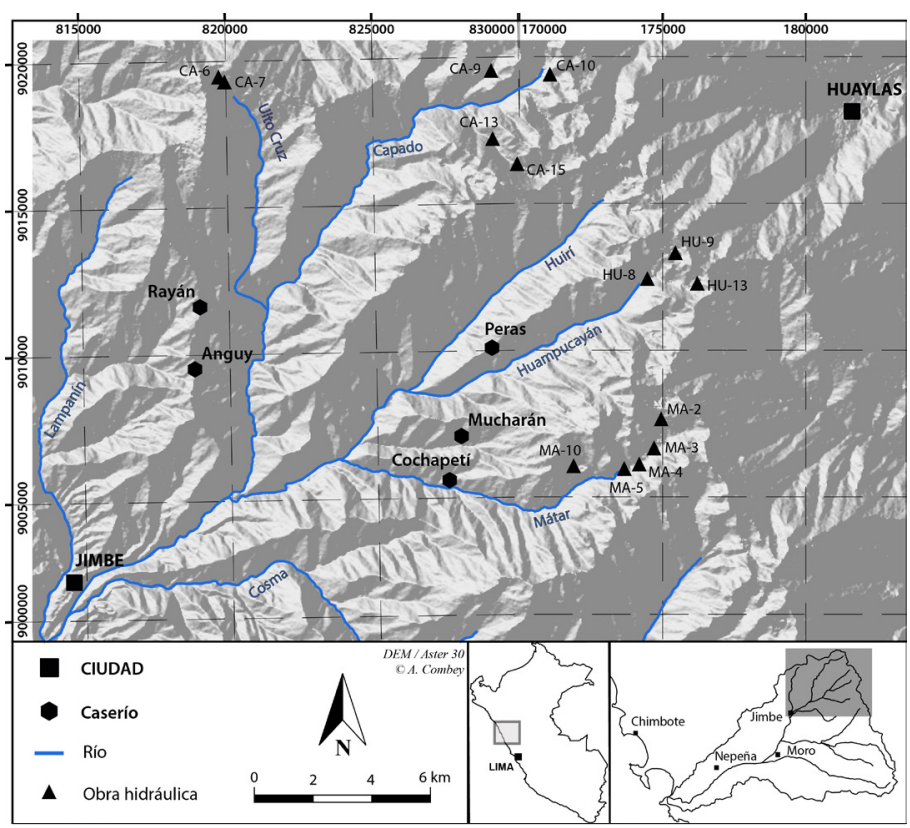

Figura 1. Valle alto de Jimbe y distribución de los sitios presentados. Créditos Andy Combey.

High Jimbe Valley and layout of sites in the article. Credit: Andy Combey. 
de esta quebrada ha sido motivo de controversia y disputa con las comunidades de Huaylas y Santo Toribio hasta hace algunos años. La raíz del conflicto ha sido esencialmente el control de los pastos y los recursos naturales del área. Las lagunas situadas en las cabeceras de esta quebrada suelen ser visitadas por los pobladores de los caseríos de ambos flancos de la Cordillera Negra por contener fauna lacustre. Debemos agregar que también se visitó un afluente de la quebrada Capado por su margen derecha, conocida como la quebrada Ulto Cruz. En la cabecera de este pequeño tributario es posible encontrar un número considerable de cabezas de ganado vacuno de pastores de los pueblos de Rayán y Racuaybamba.

La segunda, la Quebrada Huampucayán, es mencionada ya en el siglo XIX (Figura 2) por Raimondi ${ }^{5}$ (1873:111), quien señala que por ella traficaban los comerciantes de Huaylas que se dirigían a la costa ${ }^{6}$. La cabecera de esta quebrada está interconectada por una serie de lagunas que, vistas desde imágenes satelitales, conforman un conjunto de lagunas que encierran una forma circular en un radio no superior a los $1,5 \mathrm{~km}$. La superficie de esta cabecera está caracterizada por poseer una aridez extrema y generalmente rocosa. Por consiguiente, la presencia de pastos o alguna otra vegetación es de muy baja densidad. La cabecera de esta cuenca es utilizada para llegar al poblado de
Ancoracá, ubicado en el flanco oriental de la Cordillera Negra, siguiendo un sendero ubicado en el sector sur del complejo de lagunas. Este camino parece ser de considerable antigüedad y podría corresponder a la vía que refería Raimondi comentada líneas arriba. Actualmente, los pobladores de Peras y Mucharán representan los principales visitantes de estas alturas, aunque se percibe una mayor posesión del pueblo de Peras, posiblemente debido a su cercanía. No obstante, las labores de refacción realizadas a los diques de las lagunas provienen de ambos lados. Existe un marcado contraste geográfico si consideramos la zona ubicada arriba de la Laguna Quepancocha y la situada en su parte inferior. Mientras que la primera presenta principalmente una superficie rocosa con muy poca vegetación, la parte inferior a esta laguna contiene mayor cantidad de pastos, principalmente ichu (Stipa ichu).

Finalmente, la cabecera de la Quebrada Mátar, presenta la cuenca más estrecha de las quebradas identificadas. Esencialmente, posee una forma de "V" que aumenta mientras va descendiendo en sus partes medias y bajas. Contiene el mayor espejo de agua identificado, la Laguna Mamancocha, la cual presenta un dique imponente que será descrito posteriormente. Las características de esta cabecera de cuenca son similares a las del complejo Huampucayán. La parte

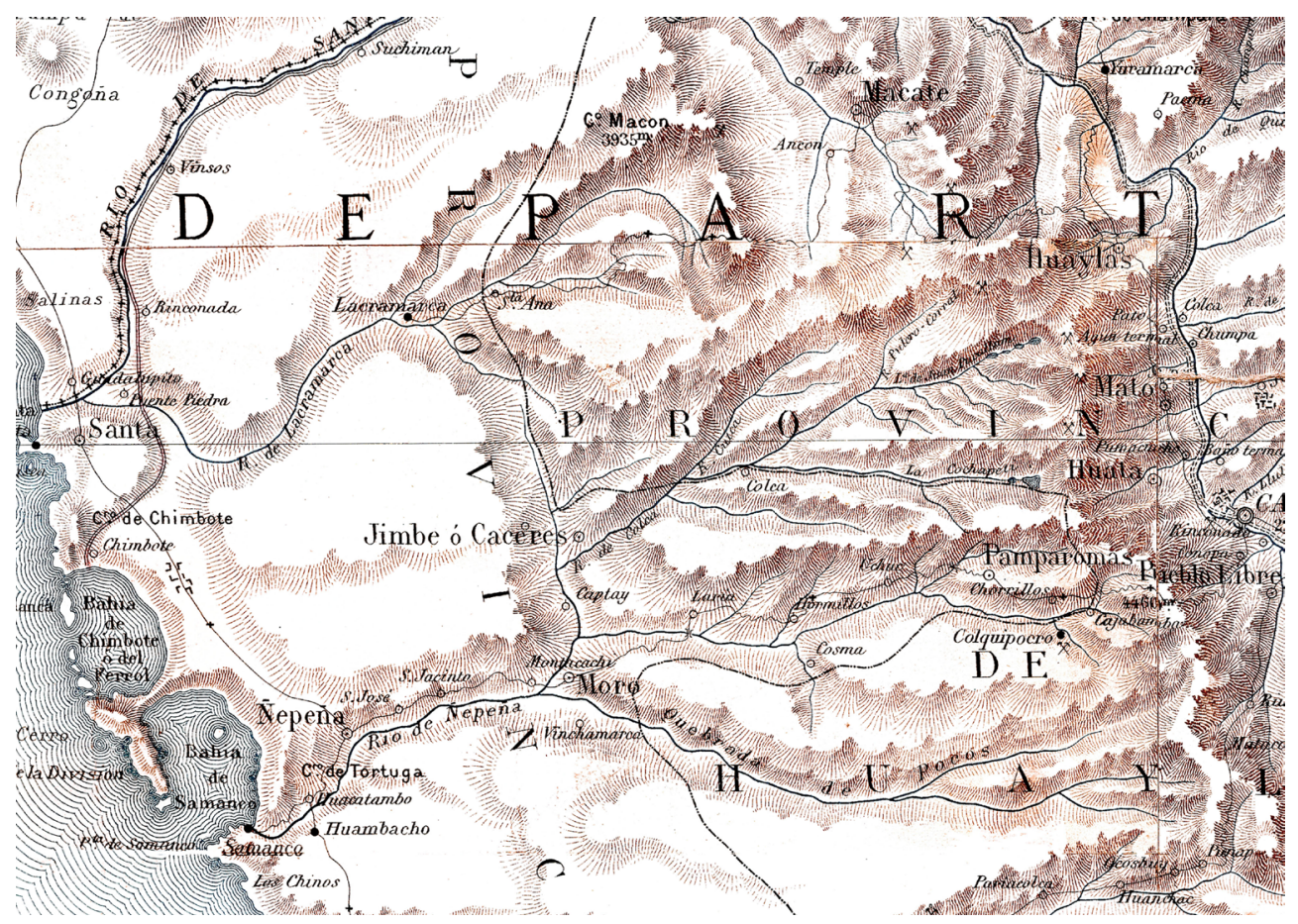

Figura 2. Extracto del mapa (Foja 16) de Raimondi correspondiente al valle de Nepeña. Mapa tomado del Archivo Museo Raimondi.

Excerpt of Raimondi's map (page 16), corresponding to Nepeña Valley. Map obtained from Raimondi Museum Archive. 
alta de esta quebrada se encuentra bajo la jurisdicción del caserío de Cochapetí, pueblo moderno que se dedica intensivamente a la minería artesanal desde hace varias décadas (Gambini 1975:36).

\section{Antecedentes de Estudio}

El estudio de las represas hidráulicas o qochas en el mundo andino ha sido indefectiblemente asignado a mecanismos realizados por las sociedades de los Andes, cuya concepción revela una estrategia de subsistencia basada principalmente en la estabilidad hídrica de su medio natural (Contreras 2010; Ortloff and Moseley 2009). Se puede asegurar que es una tecnología indígena cuyos orígenes se remontan a las épocas prehispánicas (Figura 3) (Salomon 1998). Evidencia sobre la construcción de este tipo de obras hidráulicas en la época prehispánica tardía se encuentran en relatos recogidos en la región central andina, anotado por eclesiásticos o extirpadores de idolatrías (Arriaga 1621; Ávila 1966 [1598]) y cronistas andinos (Huaman Poma 2017 [1613]). Ligado a ello se sostienen todo un conjunto de elementos cosmológicos (Boelens 2014) en el que se imbrican esencialmente la fertilidad y la relación del hombre con su naturaleza o sallqa (Grillo 1994). En el siglo XX, diversos estudios antropológicos nos muestran las prácticas ancestrales relacionadas al contexto ritual que contienen las diferentes manifestaciones regionales de estas actividades, usualmente asociadas al mantenimiento de los sistemas hidráulicos (Arguedas 1956; Carlier 2008; Farfán 2002; Gelles 1986; Mitchell 1981; Ossio 1978; Tello y Miranda 1923; Valderrama y Escalante 1988). Como lo constataron Albeck (2011) y Parcero-Oubiña et al. (2016), la construcción de represas tiene profundas implicancias en la concepción del riego mismo: este no se limita exclusivamente a la capacidad para distribuir el agua debido a que se debe vigilar, además, la cantidad de agua almacenada y controlar las pérdidas.

Evidentemente, estas estructuras tienen una lógica obvia, que podría definirse como una estrategia de aprovisionamiento del recurso hídrico en lugares de irregular flujo del mismo. Considerando que en gran parte de la zona altoandina existen dos marcadas estaciones: una de lluvias (diciembre-marzo) y la otra caracterizada por la ausencia de estas (mayo-agosto), estas estructuras contribuirán a estabilizar esa irregular condición hidrológica.

Se considera el trabajo pionero de Paul Kosok (1965) como el principal referente que aborda los sistemas de riego andinos. Este trabajo sirvió para ulteriores estudios en los Andes. Con respecto al modo de aprovisionamiento económico de los grupos prehispánicos, tenemos los postulados de Murra (2002a) que, evidentemente, muestran solo una

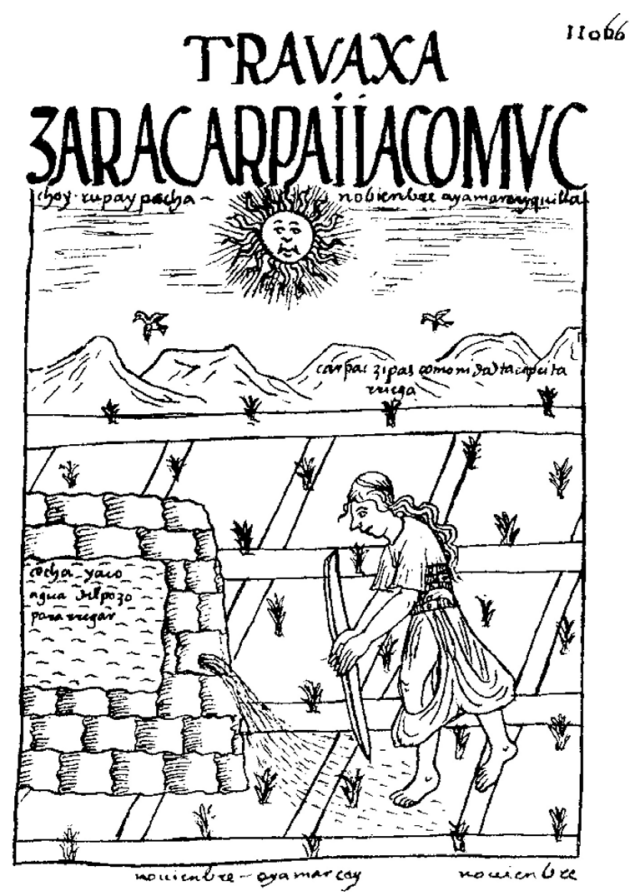

Figura 3. Reservorio de agua según Huaman Poma de Ayala. Tomado de Huaman Poma de Ayala 2017:1162.

Water reservoir according to Huaman Poma de Ayala. Taken from Huaman Poma de Ayala, 2017:1162.

estrategia de subsistencia con respecto al acopio de productos de distintas zonas ecológicas.

Si bien el presente estudio se centra en áreas ubicadas sobre los $4.000 \mathrm{msm}$, consideramos necesario conocer estos planteamientos porque debemos tener en cuenta que, como ya lo demostró Rostworowski (2006) para el Valle de Chillón, la relación existente entre las comunidades de las tierras bajas y altas siempre pudo estar relacionada. Evidentemente, en mayor medida si consideramos que obras hidráulicas como las identificadas impactarían económicamente en las poblaciones del valle bajo y medio, creando, incluso, algún escenario tenso por la apropiación del agua en las poblaciones que no disponen regularmente del recurso hídrico. Este punto de vista, que podría denominarse "perspectiva vertical de manejo de agua", ha dejado de lado las interrelaciones también desarrolladas por los grupos andinos situados a similar altitud en torno a sus recursos hídricos, pero en diferentes cuencas hidrográficas. Aquí, la evidencia atestiguada mediante canales trasvase prehispánicos en la región andina (Ortloff 1981; Osorio y Santoro 1989), como el sistema de canales Huiru Catac a nivel local (Maza 2018c), sugiere acuerdos políticos entre las comunidades aledañas. De este modo, esta investigación colige que debemos tener en cuenta perspectivas indígenas de manejo de agua, como bien lo han señalado algunos investigadores en torno al manejo integrado de cuencas 
hidrográficas (Greslou 1988; Villafana 1986). Este punto de vista, entonces, puede ser tomado en cuenta como "perspectiva horizontal".

Vivanco (2015) y Berrocal (2014) muestran, para los Andes sureños, represas hidráulicas aparentemente prehispánicas. El primero lo hace para Chincheros, Apurímac; la segunda autora hace lo mismo para Ayacucho, mostrando esta última evidencias de pagapus que denotarían el carácter ritual de dichas prácticas. Asimismo, Julio C. Tello encuentra estas obras hidráulicas en la zona alta de San Pedro de Casta, Huarochirí (Tello y Miranda 1923), brindando, además, un excepcional relato etnográfico sobre la forma de organización y el mantenimiento de los sistemas hidráulicos en las comunidades andinas de la sierra central peruana.

A nivel regional se cuentan con los estudios de Antúnez de Mayolo (1986), quien da cuenta de lagunas aparentemente represadas en las tierras altas de la provincia de Aija, en la sección central de la Cordillera Negra.

En el valle alto de Nepeña (Valle de Pamparomás) tenemos los estudios locales de Samaniego (1991) y Fauré y Peña (1999), quienes reportan la presencia de represamientos prehispánicos. Describen la técnica constructiva de estas obras y anotan datos referentes al contexto arqueológico asociado. Samaniego, incluso, propone tentativamente que la construcción de estas represas podría haberse iniciado hace 2.000 años, aunque sin argumentos convincentes que sostengan estos planteamientos cronológicos.

Recientes investigaciones sistemáticas han revelado una nutrida información referente a las infraestructuras hidráulicas, denominada por Lane (2006a) como "arquitectura hidrotécnica", bajo la dirección y manejo principalmente de agropastores, a los cuales atribuye la condición de llacuaces, siguiendo lo planteado por Duviols (1973) para la zona de Recuay y Ocros en base a documentos coloniales (Hernández Príncipe 1923 [1620]).

La obra de Lane es, sin duda, la referencia más directa y el marco comparativo que se debería tomar en cuenta considerando la cercanía con nuestra zona de estudio. Si bien sus estudios se centran en describir, analizar y comprender el funcionamiento de estas evidencias hidráulicas en relación a los pastores (Lane 2006a, 2006b; Lane y Grant 2016), permiten también dar luces sobre el patrón de asentamiento disperso que caracterizó a los grupos humanos asentados en estas altitudes durante la época prehispánica tardía (Lane 2010, 2011). Lane (2006a, 2010) afirma que a partir del Intermedio Tardío (1000-1460 DC) se incrementan las concentraciones poblacionales, principalmente en la región Suni. Es probablemente también la época en la que se construyen y/o refuerzan la mayor cantidad de infraestructuras hidráulicas reportadas para esta zona. La relación estrecha entre estas últimas y las actividades pecuarias le permite, además, proponer un predominio de los pastores sobre zonas ecológicas más extensas que en la actualidad.

Debemos señalar, asimismo, que existen informes escuetos referentes a las represas hidráulicas identificadas en la presente investigación. El primero corresponde al periodista de El Comercio, Antero Aspíllaga (1953), quien menciona la existencia de tres represas: Huanpucallan, Wari y Matará (Mátar o Mamancocha). Solo refiere que la primera posee muros de contención, y las asigna, sin análisis contextual alguno, como construcciones incaicas (1460-1532 DC).

Para finalizar, Gambini (1975) y Villafana (1986) exhiben en sus trabajos importantes registros fotográficos de los antiguos muros de las represas, cuyo análisis y revisión permitió discernir mejor las probables refacciones o modificaciones de estos antiguos muros de contención. El primer autor es quien hasta ahora ha realizado las mayores aproximaciones cronológicas del área de Jimbe, siendo su obra un documento fundamental para conocer preliminarmente el proceso ocupacional prehispánico de la zona, así como de cualquier referencia sobre las obras hidráulicas situadas en la región altoandina del distrito de Cáceres del Perú.

\section{Metodología de Investigación}

Los datos presentados y analizados en este artículo fueron recogidos durante una prospección realizada en las quebradas de Huampucayán, Mátar y Capado. Debido a la extensa área de prospección abarcada por estas tres quebradas, que sobrepasa los $160 \mathrm{~km}^{2}$, se otorgó prioridad al estudio de las obras hidráulicas prehispánicas, particularmente las represas. Una exploración previa de las imágenes satelitales del distrito nos permitió, además, definir algunas zonas de interés. Esta técnica es conocida en el ámbito de la Geomática como teledetección. Asimismo, se utilizaron principalmente los software Google Earth y SAS PLANET así como el análisis de las cartas geográficas 18-g (Santa Rosa) y 18-h (Corongo) del IGN.

En cuanto a la definición de este sistema, elegimos, siguiendo a Lanzelotti (2011:179), llamar represas a todas las estructuras "cuya función es de almacenar agua para su posterior utilización". El término "dique" será utilizado únicamente para referirnos al muro construido para retener el agua. El término "represa" será empleado en su sentido amplio abarcando el dique (restos arqueológicos) y el reservorio de agua. Se referirá a muros sumergidos, generalmente arriba del dique moderno, como rompeolas, siguiendo la denominación empleada por los pobladores locales. Estos rompeolas tendrían un papel importante en el mantenimiento de 
la integridad estructural de la represa, amortiguando la fuerza del agua transmitida al dique así como reduciendo la erosión de las riberas del embalse.

El registro se realizó mediante el llenado de fichas que contienen para cada evidencia hidráulica, las siguientes características: ubicación (coordenadas UTM y altitud), dimensiones, técnica, materiales constructivos y estado de conservación. La recopilación de estos datos permitió realizar esquemas y dibujos arquitectónicos de las obras hidráulicas. La detección de cada represa se complementó con su geolocalización en el sistema geodésico WGS 84 registrado bajo la forma de coordenadas UTM.

$\mathrm{Al}$ igual que en trabajos anteriores (Lane 2006a, 2016; Vivanco 2015), se hizo un trabajo de registro descriptivo para caracterizar las represas y así tener una mejor comprensión de su funcionamiento. A pesar de las dificultades de categorización con una preliminar observación, se decidió adoptar la tipología funcional de Lane (2006a), clasificando las represas en dos variedades: de agua y de limo. Las represas de agua sirven esencialmente para almacenar el agua producto de las precipitaciones y de las escorrentías; estas se encuentran delimitadas en su parte baja por un dique rústico generalmente de doble cara. Así, el espejo de agua ve incrementado su volumen e incluso contribuye a incrementar parcialmente el acuífero valle abajo. Generalmente se ubicaron entre los 4.100 y 5.100 msm.

Las represas de limo, aunque arquitectónicamente muy similares a las represas de agua, sirvieron principalmente para la creación y el mantenimiento de bofedales, y se ubicaron entre los 3.825 y 4.425 $\mathrm{msm}$. Cabe precisar que si bien se ha seguido la clasificación correspondiente a represas propuesta por Lane, esta investigación no considera convincente la distinción planteada por este investigador entre "represa" y "reservorio de limo". Por falta de argumento en torno al funcionamiento de esta última categoría, decidimos emplear el término único de represa.

Para la identificación y la denominación de las evidencias detectadas se utilizó una codificación geográfica. Se dividió el registro en tres, correspondiente al número de quebradas prospectadas. Se asignó a cada evidencia una combinación de dos letras y una cifra, en la cual las letras correspondían a las dos primeras de la quebrada donde se situaba la evidencia mientras que la cifra indicaba el orden del registro. Se utilizó HU-, MA- y CA- para referenciar, respectivamente, las evidencias de Huampucayán, Mátar y Capado.

\section{Descripción de las Obras Hidráulicas}

Fueron registradas 14 obras hidráulicas durante esta prospección. Se localizan en tres quebradas colindantes, sin embargo presentan características arquitectónicas diversas.

\section{Quebrada Huampucayán}

$H U-8$

Se sitúa en la Laguna Quepancocha, espejo de agua más extenso de la Quebrada Huampucayán. Se trata de una represa de agua compuesta de dos muros sumergidos, represada en la actualidad por un dique de piedras con cemento. Ambos muros son dispuestos en arco de círculo y separados entre ellos por $3 \mathrm{~m}$ aproximadamente en el medio de la laguna y por menos de $1 \mathrm{~m}$ en sus extremos, es decir, en las orillas de la laguna (Figura 4). Un canal parece conectarlos. El muro ubicado río abajo mide hasta $1,5 \mathrm{~m}$ de ancho.

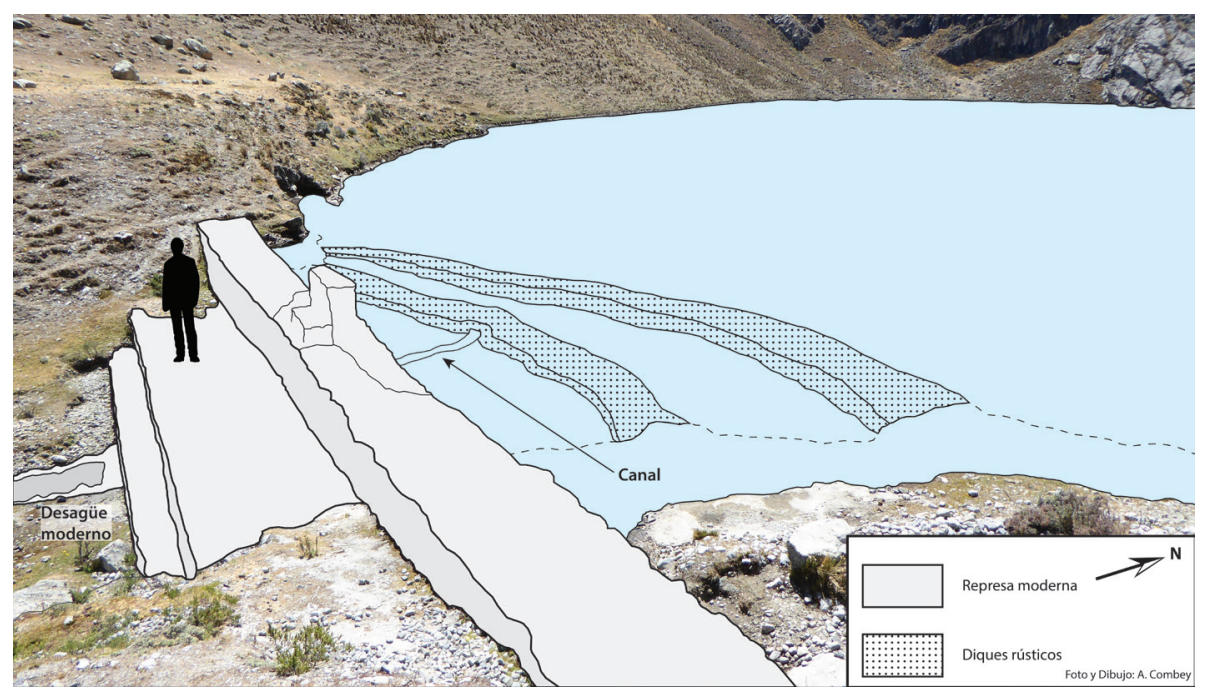

Figura 4. Represa de Quepancocha (HU-8) y detalles de los dos muros sumergidos. Dibujo realizado por Andy Combey. 
Aunque estos dos muros podrían ser interpretados como parte de un sistema de "rompeolas" construido al mismo tiempo que la represa moderna, la foto tomada por Wilfredo Gambini (1975:126) demuestra la preexistencia de estos dos muros a la construcción de la represa. Se distingue, incluso, un tercer muro en la fotografía que fue probablemente reutilizado para la construcción del dique moderno. Consideramos que corresponden a una obra de represamiento antiguo, posiblemente prehispánico.

Cabe señalar la presencia de otro muro, de $6 \mathrm{~m}$ de largo, perpendicular al curso del agua debajo de la represa moderna. Presenta una salida de agua en su base. No es claro si todos estos muros funcionaron juntos o si corresponden a diferentes fases del represamiento de la laguna. Antero Aspíllaga (1953) citando a esta represa, menciona varios muros de contención con el fin de "amortiguar la fuerza de salida".

HU-9

Corresponde a varios muros conformando el sistema de represamiento de la laguna denominada Islacocha. Se observan diques en dos sectores de la laguna. El primer sector, ubicado en la parte suroeste de la laguna, presenta una sucesión de tres muros sumergidos por el agua e interconectados por un canal. Esta sucesión de muros es muy parecida a las evidencias encontradas en Quepancocha. Los tres diques parecen presentar dimensiones y una técnica constructiva similares (Figura 5).

El segundo sector, situado en la parte sureste de la laguna, contiene dos muros de represamiento, los que a juzgar por sus características y estado de conservación actual, corresponden a dos momentos constructivos cronológicamente diferentes. El muro moderno parece adosarse sobre un muro más antiguo ubicado hacia el exterior (Figura 6). El dique "antiguo" fue construido "en seco". No se pudo constatar la presencia de un desaguie. Finalmente, el dique es ligeramente convexo en su parte externa.

\section{$H U-13$}

Se localiza en el borde suroeste de la laguna Minascocha. La laguna es probablemente llamada así por una antigua mina que fue explotada en su entorno.

Se trata, de nuevo, de un muro sumergido por las aguas represadas de la laguna. El muro de $50 \mathrm{~cm}$ de ancho está conformado por piedras semicanteadas. No podemos asegurar si se trata de un dique de época prehispánica. El muro podría corresponder a un "rompeolas" en mal estado de conservación.

Se debe señalar que existen otras dos lagunas, ambas represadas hace poco tiempo, debajo de Minascocha. No se pudo constatar evidencia de un dique más antiguo. Sin embargo, es muy probable que hayan existido obras de represamiento en estas lagunas, conforme a las informaciones recogidas en el caserío de Peras.

\section{Quebrada Mátar}

\section{$M A-2$}

Estáubicadoa $500 \mathrm{mal}$ surde laLaguna Pintadacocha, nombre derivado debido a la presencia usual de venados (comúnmente llamados "pintados") por los alrededores. Se trata de un dique que represa un pequeño espejo de agua. El muro tiene su cara interna fortalecida con concreto pero conserva su cara externa intacta. El muro está compuesto por piedras de cerro cortadas toscamente, de tamaño medio a grande (Figura 7). No se pudo constatar la evidencia de mortero. El

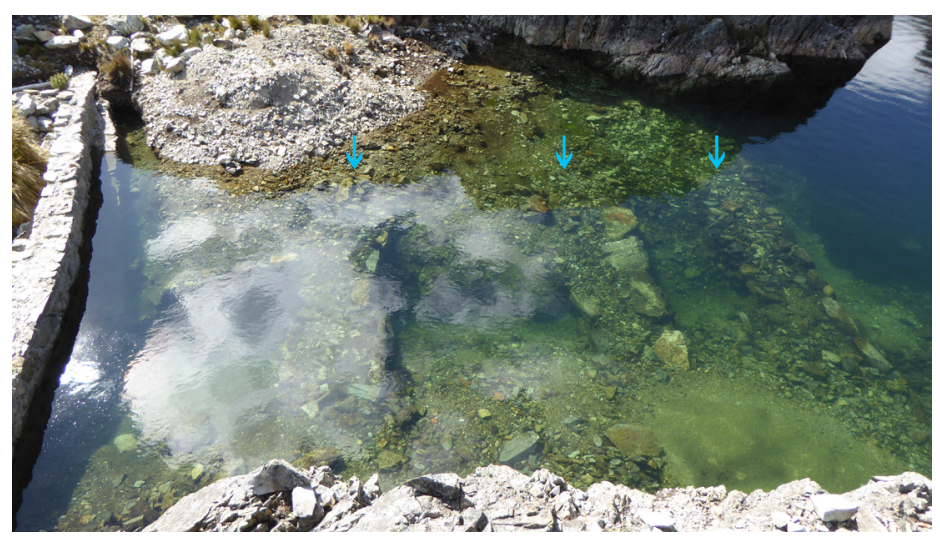

Figura 5. Muros de represamiento antiguos y dique moderno de Quepancocha, sector suroeste. Foto de Andy Combey.

Quepancocha's ancient damming walls and modern dam, southeast sector. Photo by Andy Combey. 


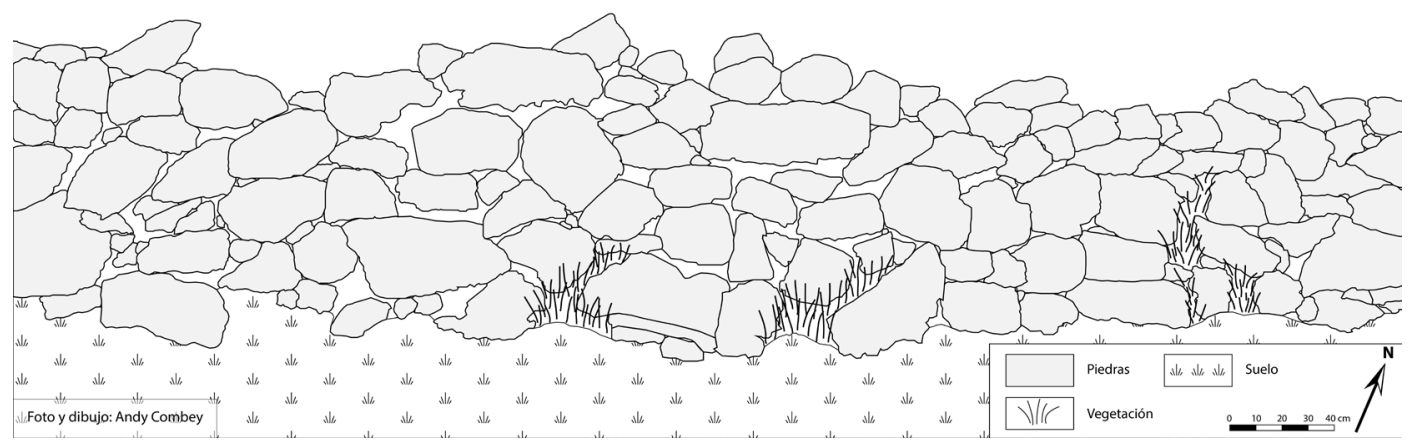

Figura 6. Cara externa del dique de la represa de Islacocha (HU-9) - sector sureste. Dibujo realizado por Andy Combey. Outer side of Islacocha dam wall (HU-9) - southeast sector. Drawing by Andy Combey.

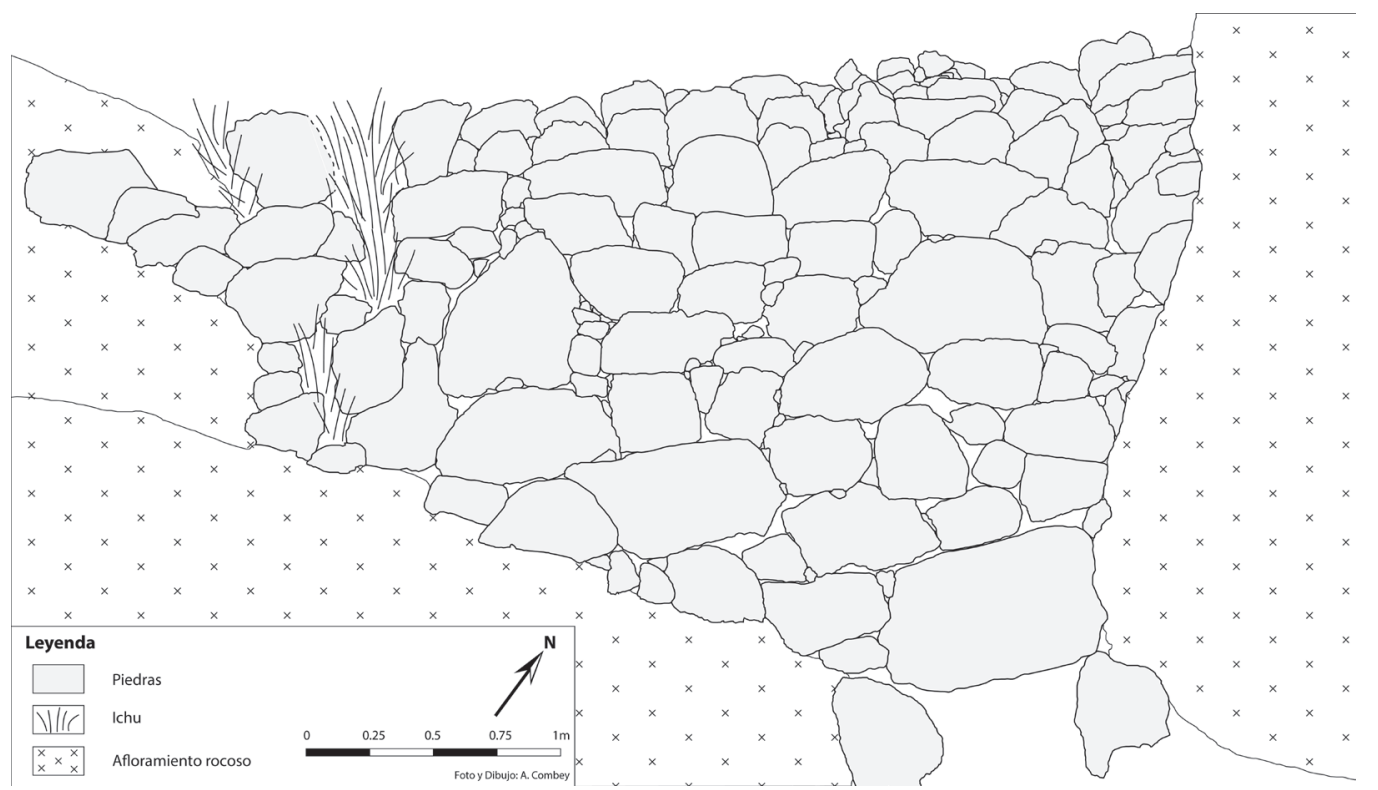

Figura 7. Cara externa del dique de la represa sin denominación (MA-2). Dibujo realizado por Andy Combey.

Outer side of wall of unnamed dam (MA-2). Drawing by Andy Combey.

dique fue edificado sobre una base rocosa y en un lugar privilegiado para el represamiento del agua por situarse en un lugar estrecho. El dique presenta además un desaguie en su base para facilitar la evacuación del agua.

MA-3

La estructura referida es un dique y represa, en la Laguna Mamancocha, la más extensa de la Cuenca de Mátar. Mamancocha significa laguna madre en quechua (Sherbondy 1982), su nombre se refiere probablemente a su posición central dentro de la Quebrada Mátar y al importante volumen que contiene el espejo de agua.
La laguna fue el lugar de un importante trabajo de represamiento comunal que aprovechó los cimientos, según Gambini (1975), del dique prehispánico. Se pudo, efectivamente, apreciar una diferencia en el método de construcción en la base del imponente dique moderno (Figura 8), confirmando la afirmación del mencionado autor.

Sin embargo, una foto tomada por Gambini (1975:22) que presenta aparentemente el dique prehispánico no concuerda con nuestras observaciones. Se puede suponer que el muro observado por el autor se encuentra sumergido por las aguas de la represa o fue destruido para construir el dique moderno.

Río abajo se observan dos muros de tipo rústico. De dimensiones reducidas, estos son también 


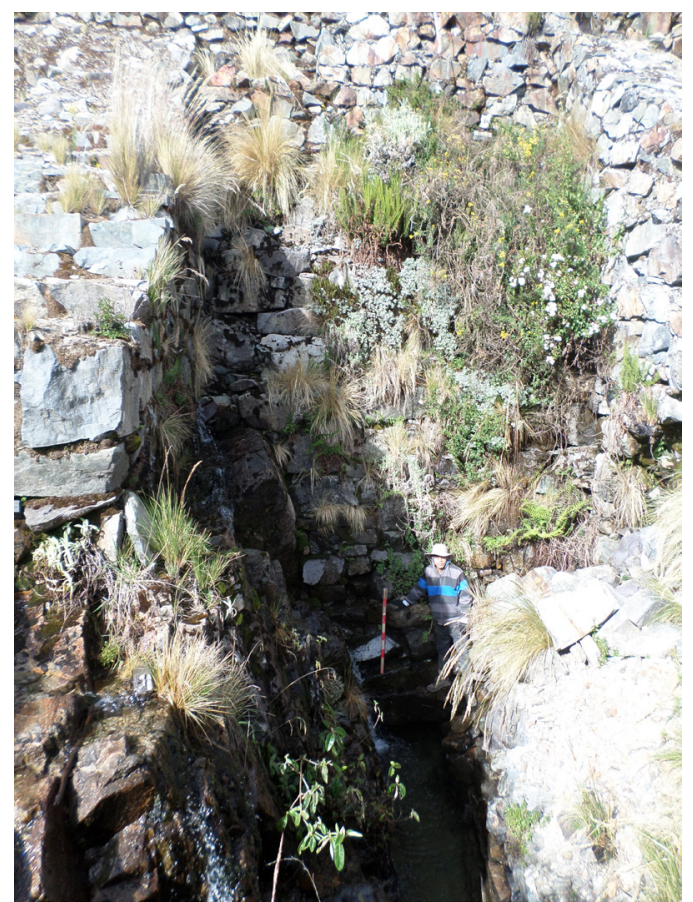

Figura 8. Cara externa del dique de Mamancocha mostrando los cimientos prehispánicos. A ambos lados nótense los contrafuertes modernos para soportar la presión hidráulica (MA-3). Foto de Jesús Maza.

Outer side of Mamancocha dam wall showing pre-Hispanic foundation. Note the modern buttresses to support the hydraulic pressure (MA-3). Photo by Jesús Maza.

perpendiculares al curso del agua y presentan cada uno una salida de agua en su base. La ausencia de cemento y mortero recuerda el método de construcción constatado en los ejemplos anteriores, particularmente HU-8. Sirven actualmente como pequeños puentes para cruzar hacia ambos lados del curso de agua que baja de la laguna.

\section{$M A-4$}

Se ubica en el extremo sur de la laguna denominada Chaupicocha. El nombre proviene de los términos quechua "chawpi" y "qucha", es decir, "laguna del medio", refiriéndose indudablemente a su posición geográfica. Está localizada río abajo de la Laguna Mamancocha.

MA-4 corresponde a un muro sumergido por las aguas de la laguna. La parte visible del muro mide alrededor de 5,5 $\mathrm{m}$ de longitud y 1,3 $\mathrm{m}$ de ancho. Las piedras que lo conforman no han sido trabajadas. No se puede afirmar con certeza que corresponda a una antigua obra de represamiento, pero la similitud con las otras evidencias mencionadas nos conduce a plantear tal hipótesis.

\section{$M A-5$}

Se localiza en el sector suroeste de la represa de Quepancocha. En la parte superior del dique moderno de la represa Quepancocha, laguna cuyo nombre significa "laguna de atrás" en quechua, se ve un muro en mal estado de conservación. Este último, que mide menos de $1 \mathrm{~m}$ de altura, se pudo observar gracias al nivel extremamente bajo del agua de la laguna en periodo de estiaje (Figura 9).

Bastante destruido en su parte central, el muro está construido con piedras cortadas toscamente de cerro y sin mortero (tal vez eliminado por el agua). Debido a su tamaño insignificante frente al dique moderno no puede ser considerado como un "rompeolas". Creemos que este vestigio es lo que queda de un dique antiguo. No se nota la presencia de la compuerta, quizás ubicada en la parte destruida.

$M A-10$

Se ubica en una planicie que domina el curso del Río Mátar, llamada Saquipampa, a 4.050 msm. La estructura se define como un alineamiento de grandes piedras, que superan los $2 \mathrm{~m}$ de lado. Estas piedras conforman una pequeña loma detrás de cual se acumula el agua, aunque se pueden apreciar grandes bloques derrumbados que quedaron en su emplazamiento natural. Consideramos que esta estructura constituye un tipo de dique rústico que permitió almacenar agua y, además, pudo funcionar como una represa de limo. Piedras de tamaño menor fueron colocadas ex profeso entre los bloques para construir el dique. Se perciben por lo menos otros cuatro alineamientos de piedras paralelos al primero (Figura 10). Este sistema recuerda los reservorios de limo presentados por Lane (2006a), que facilitan la retención sucesiva y continua de los sedimentos.

El paisaje en el cual se inserta esta estructura concuerda con su denominación (Chaki-pampa o pampa seca). Se pueden observar, asimismo, restos de viviendas y de estructuras de piedra próximas, cuya afiliación cronológica es desconocida. Los pobladores actuales del caserío de Cochapetí afirman que estas estructuras cumplieron una función habitacional utilizada por los mineros que explotaban los yacimientos mineros cercanos.

\section{Quebrada Capado}

\section{CA-6}

Esta estructura se ubica en la cabecera de un tributario de la Quebrada Capado, la Quebrada de Ulto Cruz, específicamente en el sector conocido como Cushuro.

El muro identificado forma parte de una represa de limo de alrededor de $9.500 \mathrm{~m}^{2}$. El muro desempeña la función de trampa para los sedimentos que se van acumulando detrás del dique, formando así un bofedal muy favorable para la actividad pastoril. Las piedras 


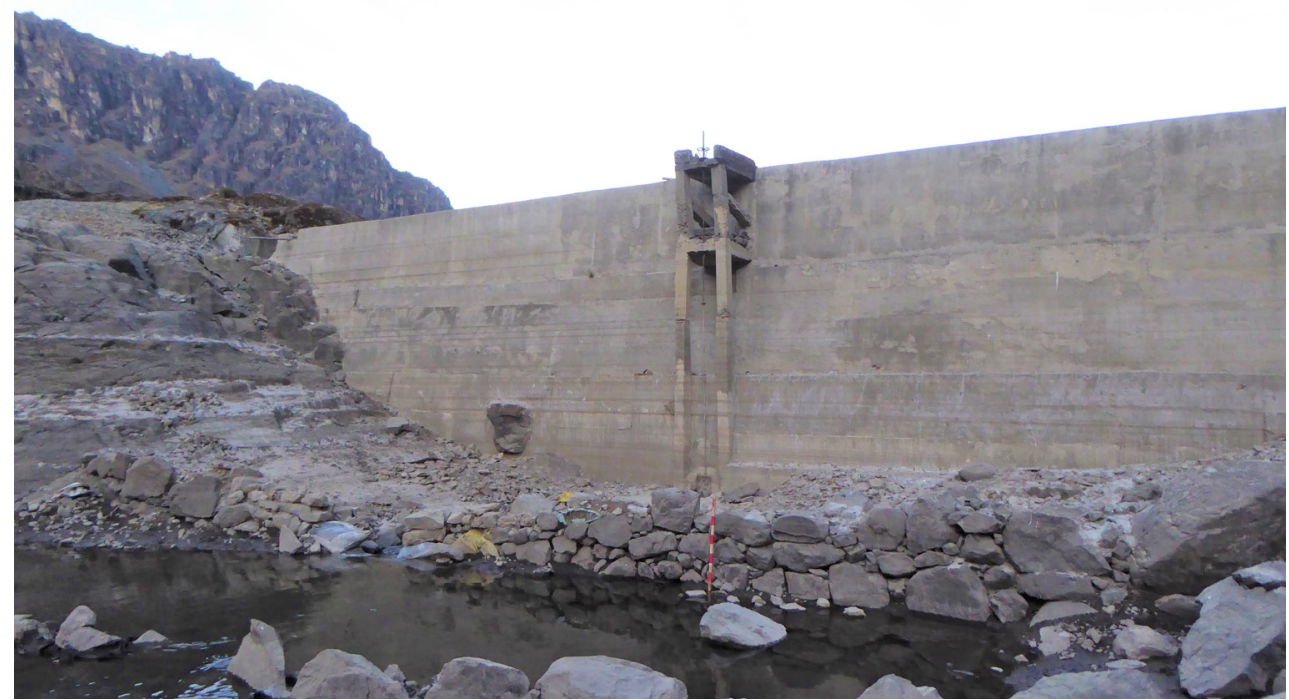

Figura 9. Dique interno de la represa de Quepancocha (MA-5). Foto de Andy Combey.

Internal wall of the Quepancocha dam (MA-5). Photo by Andy Combey.

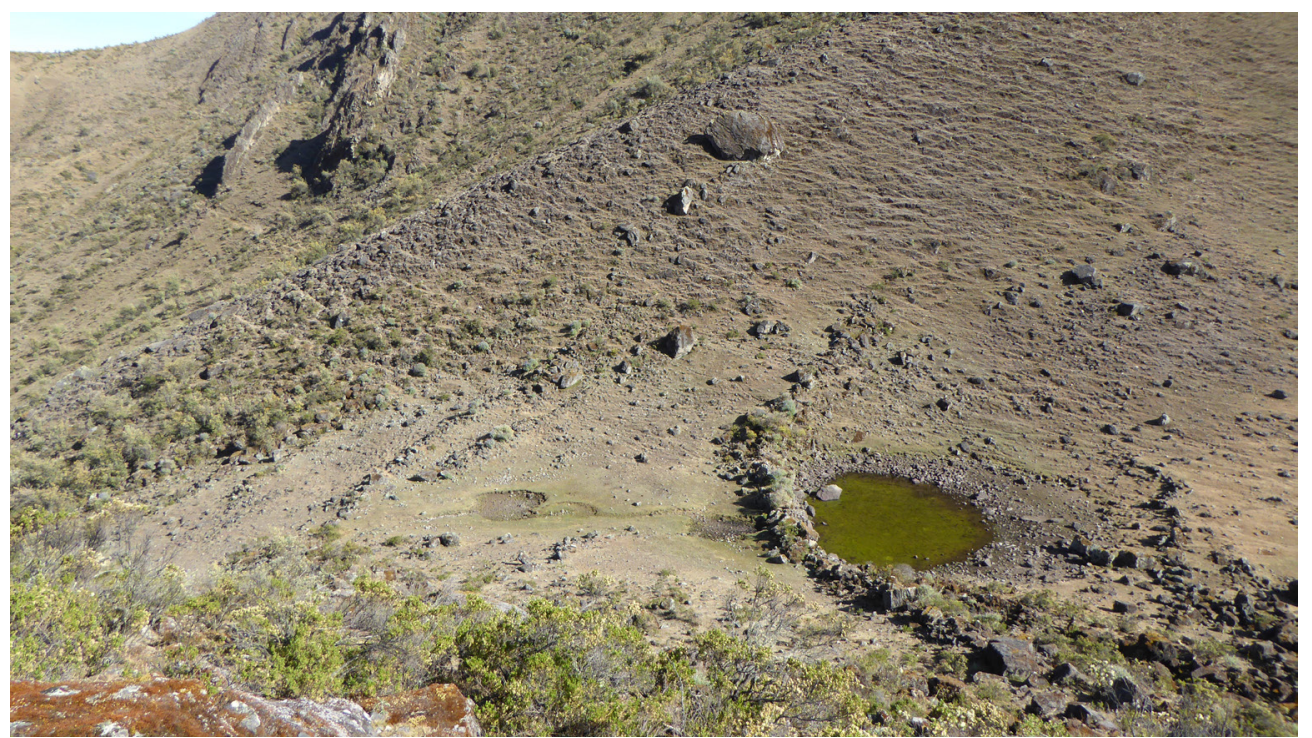

Figura 10. Dique de la represa de Saquipampa (MA-10). Foto de Andy Combey.

Saquipampa dam wall (MA-10). Photo by Andy Combey.

aparentemente no fueron trabajadas, siendo evidente una mampostería simple. Con su forma curvada hacia su parte externa, parece aprovechar al máximo del espacio disponible.

\section{$C A-7$}

Se ubica $100 \mathrm{~m}$ abajo de CA-6. CA-7 es semejante al caso anterior y corresponde a otra represa de limo de dimensiones ligeramente superiores. El método constructivo sigue el mismo patrón referido ya que el muro se compone de piedras semicanteadas dispuestas sin aparejo aparente (Figura 11). El bofedal arriba del dique cubre un área aproximada de $4.500 \mathrm{~m}^{2}$.

\section{CA-9}

Se encuentra al pie de la cumbre más elevada de la Cordillera Negra, el Coñocranra y delante de la laguna del mismo nombre. 


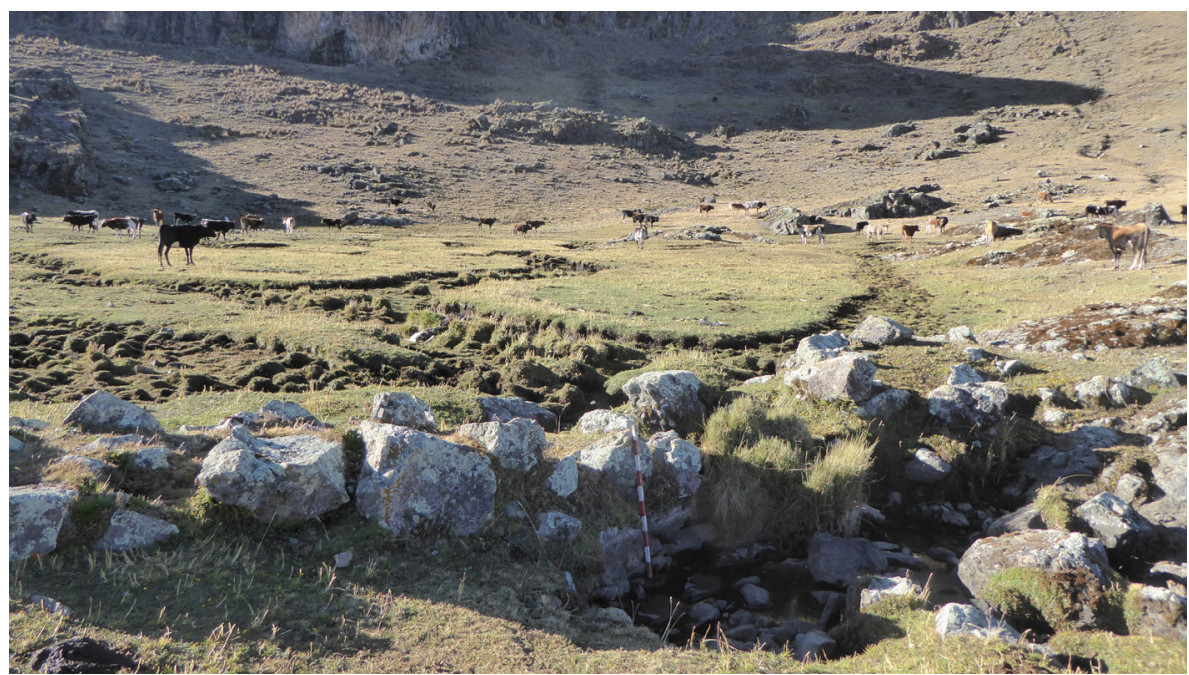

Figura 11. Dique de la represa de limo CA-7. Foto de Andy Combey.

CA-7 silt dam wall. Photo by Andy Combey.

Corresponde a un dique represando la laguna y, por consiguiente, elevando su nivel de almacenamiento (Figura 12). Esta estructura está conformada por piedras naturales, de tamaño medio a grande. Sus dimensiones son sustanciales, ya que tiene una longitud de $62 \mathrm{~m}$ de largo y una altura máxima que supera los $3 \mathrm{~m}$. Se observa, asimismo, un desagüe en la base del dique. Es posible que aquí se haya iniciado el sistema hidráulico Huiru Catac (Maza 2018c).

Etimológicamente, Coñocranra es un topónimo quechua compuesto que podría traducirse como piedras volcánicas calientes (Gambini 1975:23).

\section{CA-10}

Está localizado unos metros arriba de la carretera hacia Huaylas (AN-103), en las inmediaciones de la laguna denominada Tocanca. El sitio comprende un dique y tres recintos cuadrangulares.

El dique que represa la Laguna Tocanca está compuesto de piedras irregulares medianas (Figura 13). Mide aproximadamente $20 \mathrm{~m}$ de largo y $1 \mathrm{~m}$ de ancho.

La represa demuestra al menos dos fases constructivas. Se nota el "enrasado" de una pared río arriba, sobresaliendo del suelo $20 \mathrm{~cm}$ como máximo y

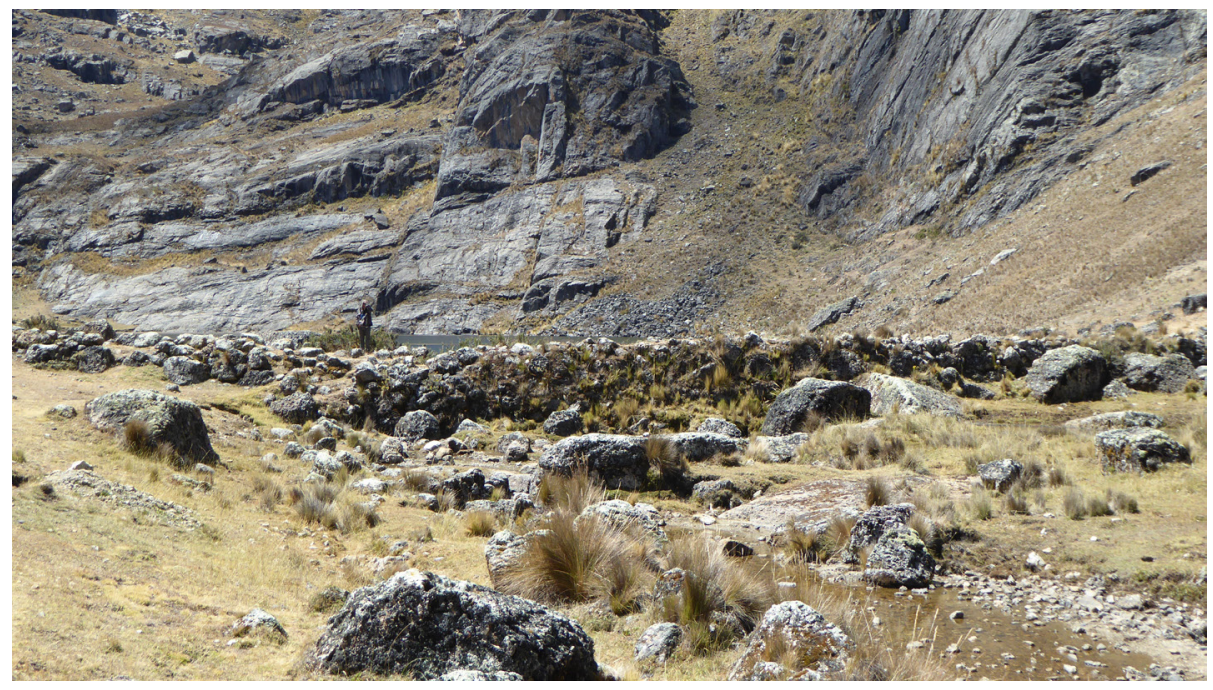

Figura 12. Dique de la represa de Coñocranra (CA-9). Foto de Jesús Maza.

Coñocranra dam wall (CA-9). Photo by Jesús Maza. 


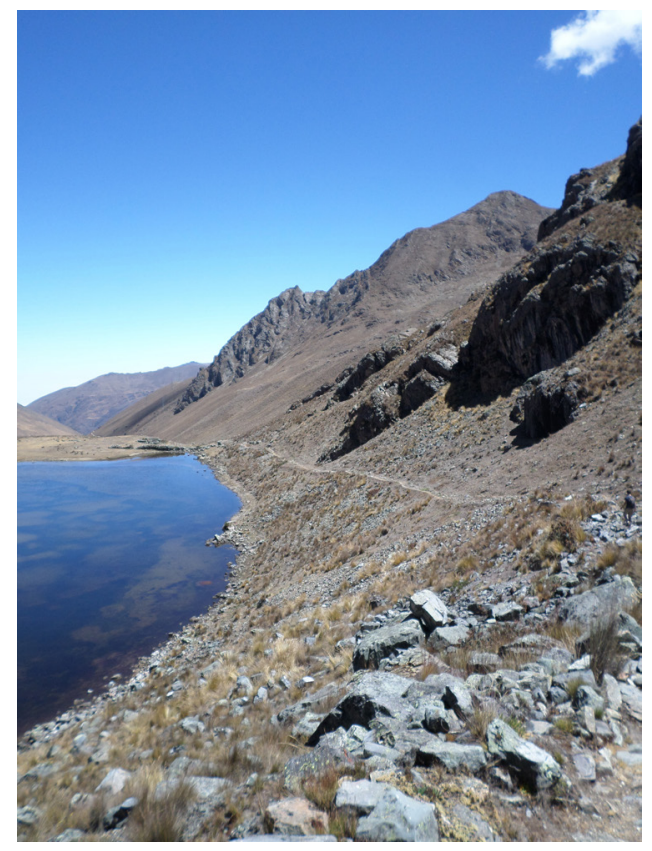

Figura 13. Panorámica de la Laguna Tocanca. Nótese el dique, el espejo de agua y el camino antiguo, probablemente prehispánico (CA-9). Vista E-O. Foto de Jesús Maza.

Panoramic photo of the Lake Tocanca. Note the dam wall, the water mirror, and the possibly pre-Hispanic old road (CA-9). EW view. Photo by Jesús Maza.

sobre la cual parece adosarse el dique más visible. El dique está parcialmente destruido en su parte central, donde se ubicaba probablemente una compuerta. En el lado oeste de esta laguna, se ubican unos recintos aparentemente modernos, cuya función aún no ha sido determinada.

\section{CA-13}

Se ubica en la parte septentrional de la Quebrada Huirí, unos $100 \mathrm{~m}$ debajo de la trocha de acceso. CA13 corresponde a un muro de baja altura, inserto en un bofedal y perpendicular al curso del riachuelo. La estructura parece facilitar el crecimiento del bofedal en esta angosta parte de la quebrada (Figura 14). La superficie de la zona húmeda, arriba del muro, alcanza $\operatorname{los} 7.000 \mathrm{~m}^{2}$.

Mientras el muro mide $10 \mathrm{~m}$ de largo, su altura es difícil de estimar ya que el bofedal ha crecido a cada lado del dique. Gracias al corte realizado por el río, consideramos que sobrepasa los 1,5 $\mathrm{m}$ de altura. $\mathrm{Al}$ oeste de la estructura, en la continuación del dique se encuentra un grupo de recintos de forma irregular y semi-circular, en mal estado de conservación. Estas estructuras se asemejan a un asentamiento temporal de pastores (Combey 2018a:38-39). Tomando como punto de partida este asentamiento y paralelamente al río se despliega, además, un muro de piedra rustico. De $300 \mathrm{~m}$ de largo, la estructura recuerda una práctica tradicional de cosecha de agua denominada "clausura de praderas" (PACC 2014:18) (Figura 15).

\section{$C A-15$}

Llamado también Huirí, debido a su proximidad con la laguna homónima, la obra se sitúa en la parte superior de CA-13. Se trata de un dique construido con piedras toscamente canteadas. Este muro permite una gestión del flujo de agua saliendo de esta extensa laguna.

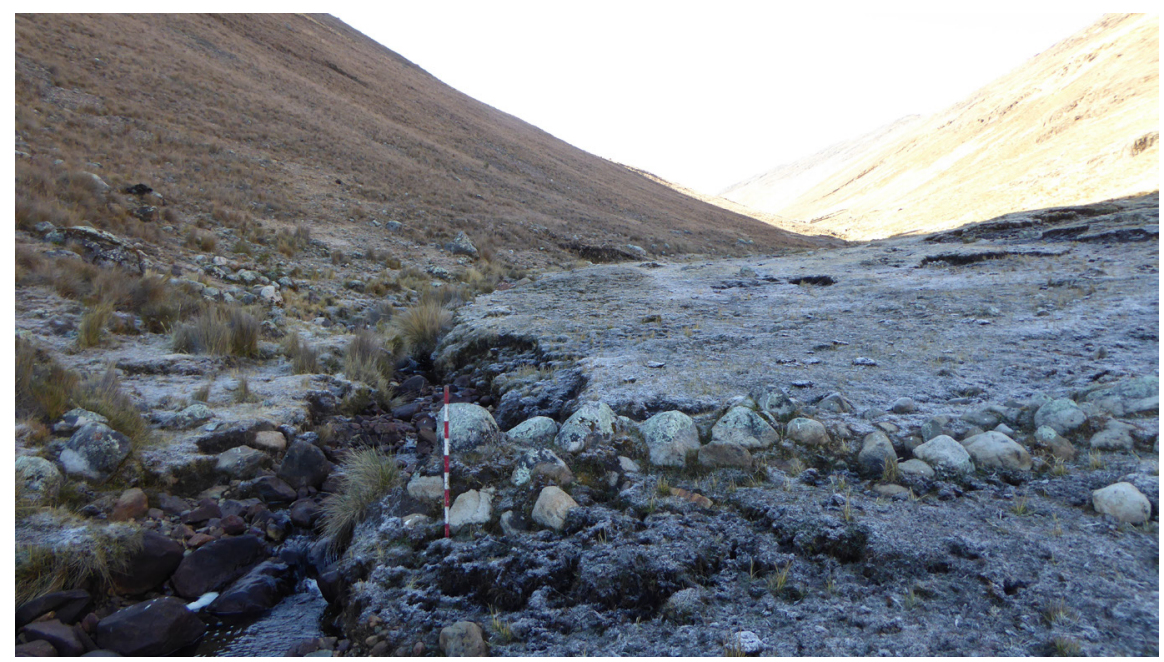

Figura 14. Muro perpendicular al curso de agua que desciende de la Laguna Huiri. Sirvió para retener la humedad y crear el bofedal. Foto de Andy Combey.

Wall perpendicular to the watercourse that flows down from the Lake Huiri Lagoon. It was used to retain moisture and create the cushion bog. Photo by Andy Combey. 


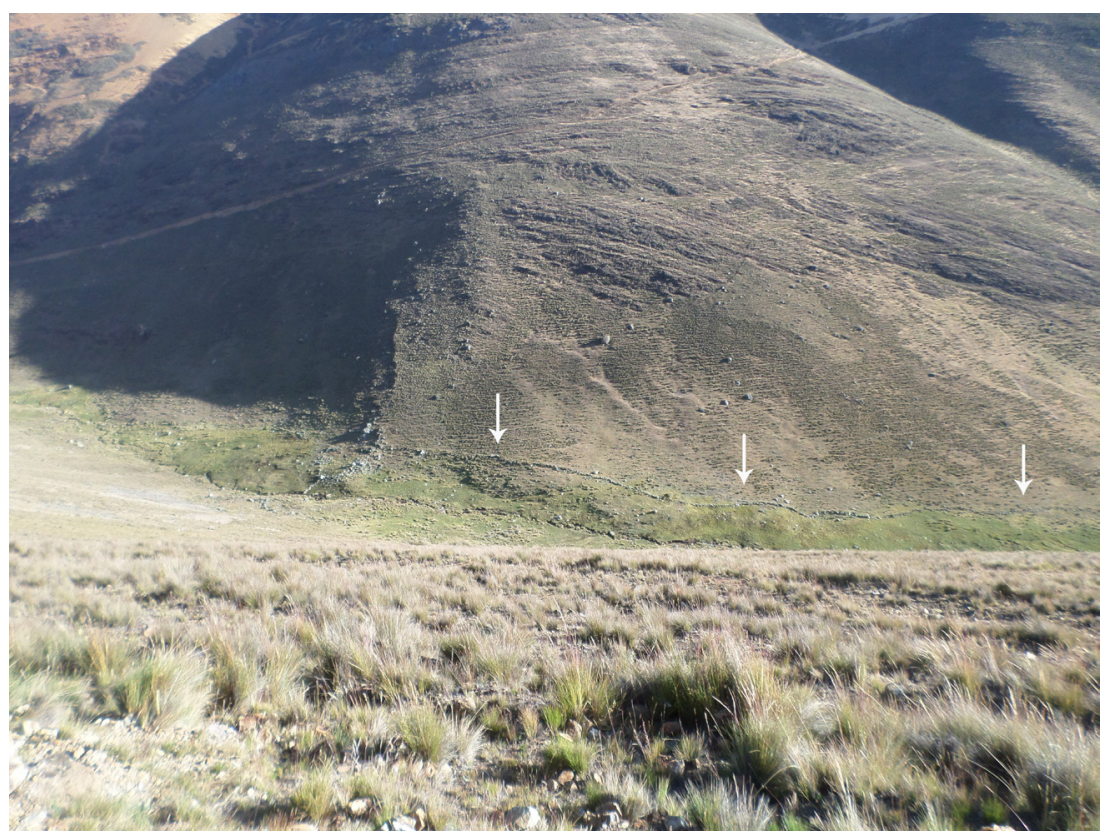

Figura 15. Alineamiento de piedra delimitando el bofedal debajo de la Laguna Huiri. Nótese el cambio de textura y color de la superficie hacia ambos lados del muro. Vista NE-SO. Foto de Jesús Maza.

Rock alignment delimiting the cushion bog under the Lake Huiri. Note the change in the texture and color of the surface towards both sides of the wall. NE-SW view. Photo by Jesús Maza.

El desagüe observado en la fotografía de Gambini (1975:21) y ubicado en la parte central del dique ha desaparecido debido al mal estado de conservación de la represa.

\section{Discusión}

Esta investigación permite proponer la existencia de varias estrategias del manejo del agua en un área tan reducida como el valle alto de Jimbe. De hecho, las estructuras previamente descritas nos ofrecen un panorama heterogéneo no necesariamente excluyente. Se distingue la existencia de dos grupos que presentan características diferentes: (1) las quebradas de Huampucayán-Mátar y (2) la Quebrada de Capado (Figura 16).

En primer lugar, las características geomorfológicas en las dos primeras quebradas tuvieron implicancias en la configuración de la red hidrográfica. En ambas quebradas las lagunas conforman una red en la cual cada laguna desemboca en la ubicada pendiente abajo, formando una configuración en serie. Las poblaciones altoandinas aprovecharon aparentemente eso para edificar represas interconectadas en Huampucayán y Mátar. Esta red presenta dos ventajas principales: primero, la construcción de obras de almacenamiento en serie aumenta considerablemente el potencial de acumulación del agua en tiempo de lluvias; segundo, la construcción en serie otorga una mayor seguridad y flexibilidad en el manejo de los recursos hídricos de la cuenca. Llenando de manera diferenciada los diferentes embalses de la red, las poblaciones pueden entonces enfrentar un intenso episodio de lluvia o incluso el colapso de un dique sin mayor consecuencia río abajo.

Frente al medio sumamente rocoso y estrecho de ambas quebradas, consideramos que las poblaciones prehispánicas supieron aprovechar de estos complejos de lagunas, represando e interconectándolas por medio de acequias (Gambini 1975:23), para aumentar el rendimiento y la extensión de las áreas cultivadas al pie de las quebradas y también amortiguar la intensidad de lloqllas $^{7}$ potenciales.

Ambas quebradas nos muestran, evidentemente, un esfuerzo por represar las aguas orientadas a satisfacer las necesidades principalmente agrícolas de las partes bajas. La continuación de las intervenciones, sobre todo refacciones a los diques, proporciona elementos a considerar para postular que la misma preocupación la tuvieron los grupos culturales ubicados en las partes inmediatamente inferiores a las represas de ambas quebradas. Además, la identificación de acequias modernas, cuya bocatoma nace en las quebradas que reciben el desagüie de las lagunas, refuerza tal hipótesis8. Sin embargo, no se debe olvidar la presencia, en la Quebrada de Mátar, de una represa de limo (MA-10), que puede sugerir, asimismo, la intromisión de elementos 


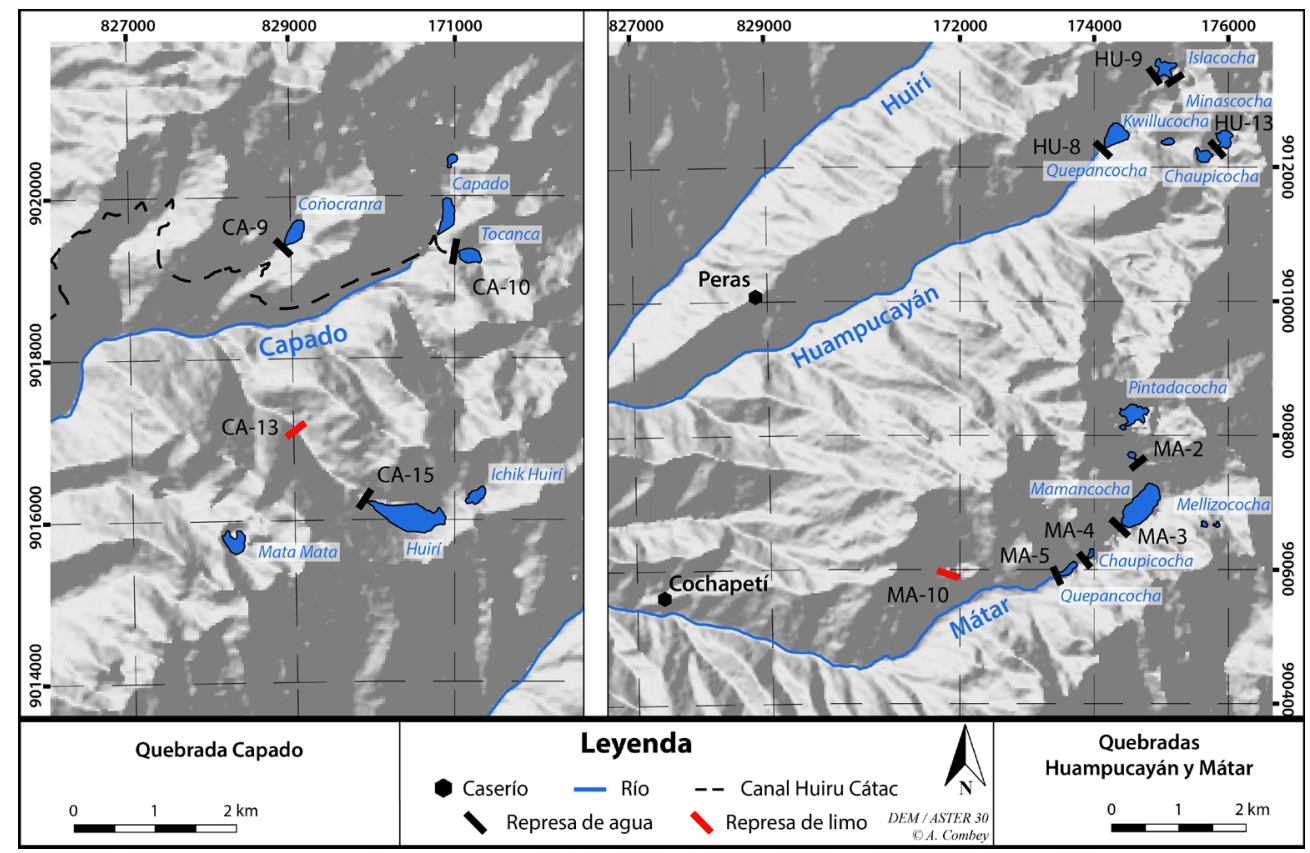

Figura 16. Distribución comparativa de las represas en las quebradas de Capado, Huampucayán y Mátar. Mapa realizado por Andy Combey.

Comparative distribution of dams in the Capado, Huampucayán, and Mátar sub-valleys. Map by Andy Combey.

agropastoriles en un área aparentemente más enfocada en la agricultura.

La Quebrada Capado presenta una situación distinta. Como se pudo constatar, las lagunas de la quebrada están dispersadas en varias "microcuencas" que alimentan la Quebrada Capado. Estas pequeñas depresiones que albergan las lagunas se caracterizan por sus extensas praderas de puna, generalmente de una pendiente suave a moderada. La topografía suave permite que las infiltraciones de agua proveniente de las lagunas represadas favorezcan sin duda la formación de las numerosas zonas húmedas ubicadas en las cabeceras de la quebrada. Estos bofedales están presentes en las inmediaciones de las lagunas de Tocanca, Coñocranra y Huirí, presentando, las tres, una transformación antrópica de carácter pastoril. La implementación de este tipo de obras hidráulicas en tal configuración geográfica supone aparentemente que los represamientos de la Quebrada Capado tuvieron como función principal el aumento de las superficies de bofedales y así el refuerzo de las actividades pastoralis. La tensión existente entre las comunidades aledañas de ambos lados de la Cordillera Negra hasta hace pocos años por controlar esta importante zona ecológica, rica en pastos naturales, refuerza su relevancia económica pecuaria. Tres indicadores significativos enfatizan, según nuestro punto de vista, el carácter eminentemente pastoral de las actividades llevadas a cabo en esta zona.

Primero se constató que entre las cuatro represas supuestamente de limo, es decir, concebidas para crear o extender una zona húmeda tipo bofedal, tres (CA-6, CA-7 y CA-13) están ubicadas en la quebrada de Capado. En segundo lugar, las cabeceras de la Quebrada Capado cuentan con un mayor número de corrales y chozas abandonadas que las dos restantes (Combey 2018a:75). Finalmente, aunque no forman parte de los datos recogidos en esta específica investigación sobre represas, el dato contextual de la Quebrada Capado permite conocer la existencia de un canal hidráulico, denominado canal I, cuya función fue irrigar un espacio ecológico tipo bofedal. Esta acequia, característica hidráulica poco conocida en la investigación arqueológica, permite reforzar el carácter agropastoril de esta quebrada para la época prehispánica tardía (Maza 2018c:8485). De hecho, regar pastos y cabeceras de quebradas tiene su correlato en la documentación etnohistórica (Garcilaso de la Vega 1918 [1609]:118; Huaman Poma de Ayala 2017 [1613]:422-423) y etnográfica (Palacios 1977). Conocidas como irpa en la comunidad aymara de Chichillapi (Puno), representan aún en la actualidad una técnica tradicional de irrigar pastos, aunque cada vez menos practicadas en comunidades altoandinas (Palacios 1977). 
Además, es significativa la presencia, en esta cabecera de cuenca, del origen de un notable sistema de irrigación, llamado Huiru Catac (Maza, 2018a), cuya naturaleza y esfera de interacción, involucró, sin duda, a las comunidades prehispánicas ubicadas en la zona interandina de los valles de Jimbe, Lacramarca y Kiway (Macate). Cabe preguntarse si la escala monumental de un sistema de irrigación como este no habría necesitado de la participación, en la etapa constructiva, de grupos provenientes de los valles bajos de Nepeña, Kiway y Lacramarca, áreas donde finalmente llegaría el flujo hídrico. Sobre el particular, Gonzales (2018) ofrece algunos indicios que relacionan las lagunas de la parte alta de Pamparomás con los grupos bajos de la cuenca del Río Nepeña, sugiriendo a partir de evidencias y relatos etnográficos, que la presencia de grupos foráneos en algunas tradiciones orales delate efectivamente la participación de grupos costeños en la construcción de la infraestructura hidráulica altoandina. Mayores apreciaciones sobre la participación de grupos costeños en las construcciones de obras hidráulicas de la Cordillera Negra podrán plantearse a partir del reconocimiento de indicadores culturales convincentes que apoyen estos interesantes planteamientos; no obstante, Rostworowski (2006) ya demostró, para otros valles, la compleja y variante relación que tenían los grupos culturales costeños con las obras hidráulicas localizadas en la cabecera de las cuencas del Pacífico.

En cuanto a la Quebrada Capado, se debe señalar que la presencia de un camino antiguo, probablemente una nueva ruta transversal para ir desde el presunto centro provincial inca ubicado en los alrededores de Huaylas (Doughty 1970; Varón 1980) hacia la zona de Tocas (Mogrovejo 1920; Zuloaga 2012), y la presencia de asentamientos incas (Combey 2018a; Maza 2018a, 2018c), provee de un marco interesante para realizar estudios intensivos y evaluar las ocupaciones tardías de la zona de estudio. Asimismo, el paso de altura de la Quebrada Capado hacia el flanco oriental de la Cordillera Negra se conoce como paso de Tocanca. Este topónimo, según referencias etnohistóricas (Arriaga 1621:37), alude a los lugares donde antiguamente se realizaban ritos, masticando y escupiendo la coca, generalmente en los afloramientos rocosos y rocas escarpadas, paisaje que fácilmente se acomoda al actual. La presencia de cruces en el paso de Tocanca, probable evidencia del sincretismo de ambas religiones, refuerza tal hipótesis.

Para finalizar, es probable que la cabecera de la Quebrada Capado, debido a sus características geomorfológicas y por ubicarse en una ruta probablemente utilizada por los incas, haya recibido mayor impacto a la llegada del Tawantinsuyu, conociendo la prominente atención que tuvieron los incas por incrementar los insumos para su notable industria textil (Murra 2002b), contexto que viene siendo reconsiderado desde los estudios de Lane (2006a, 2011) en la zona de Pamparomás. La puntual referencia que realizan los primeros observadores europeos con respecto a la presencia de considerables cantidades de camélidos en la sierra ancashina, sin duda, confirma dicho escenario (Estete 1891 [1534]; Mogrovejo 1920; Sancho 1917).

Otra diferencia importante se pudo percibir entre las obras hidráulicas desde el punto de vista arquitectónico. Mientras que la mayoría de las represas de los complejos de Huampucayán y Mátar presentan múltiples diques, en Capado esta técnica constructiva no ha sido comprobada (Tabla 1). Si estos múltiples diques fueron testigos de varias remodelaciones o de sistemas diferentes de almacenamiento del agua, nos parece un importante indicador de un manejo y de una concepción diferente entre estas dos áreas. Parece lógico pensar que las represas ubicadas en las dos primeras quebradas (Huampucayán-Mátar), debido a su continuo uso eminentemente agrícola por las sucesivas comunidades ubicadas valle abajo, hayan sido objeto de sucesivas refacciones a través del tiempo.

Al mismo tiempo, la Quebrada de Capado muestra, en esencia, un panorama distinto. Al deshabitarse los importantes núcleos poblacionales tardíos (Combey 2018a; Maza 2018c), ubicados en zonas de puna, durante las primeras épocas coloniales y, la consecuente disminución de las actividades pastoriles de esta zona, las obras hidráulicas fueron probablemente abandonadas. Asimismo, el abandono del sistema de canales Huiru Catac habría sido otro de los factores que disminuyeron la atención sobre esta otrora importante área ecológica.

El análisis contextual realizado nos lleva a sugerir la existencia de un manejo diferenciado del recurso hídrico en el valle alto de Jimbe, aunque no excluyente. Como lo ha notado Lane (2006a) para las quebradas de Chaclancayo (agropastores) y Loco (agricultores mixtos), la distribución de un número destacado de represas a lo largo de las cabeceras del valle alto de Nepeña no era concomitante de un objetivo único y común. Así, el "manejo diferenciado" debe ser entendido en los términos de productividad, es decir, las comunidades prehispánicas altoandinas se inclinaron por la actividad que mejor se acomodaba a sus condiciones medioambientales y socioeconómicas. Esto no implica que actividades pastoriles no se hayan podido desarrollar en quebradas orientadas a la agricultura, como lo atestigua la represa de limo Saquipampa en el área de Mátar. De hecho, remarca el carácter agropastoril del valle alto de Nepeña durante la época prehispánica tardía.

Esta conclusión nos lleva a otra interrogación: ¿La construcción de este tipo de obras hidráulicas en el valle 
Tabla 1. Resumen de las evidencias presentadas y sus características principales. Realizada por Andy Combey. Summary of pieces of evidence presented and their main characteristics. Prepared by Andy Combey.

\begin{tabular}{|c|c|c|c|c|c|c|c|c|c|}
\hline Código & Nombre & Norte & Este & Zona & $\begin{array}{l}\text { Altitud } \\
(\mathrm{msm})\end{array}$ & Tipo & $\begin{array}{l}\text { Dimensión } \\
\text { (L x An x Al) }\end{array}$ & Desagüe & $\begin{array}{l}\text { ¿Diques } \\
\text { múltiples? }\end{array}$ \\
\hline HU-8 & Quepancocha & 9012399 & 174380 & $18 \mathrm{~S}$ & 4.370 & Agua & $30 \times 1,5 \times ?$ & $\mathrm{x}$ & $\mathrm{X}$ \\
\hline HU-9 & Islacocha & 9013280 & 175276 & $18 \mathrm{~S}$ & 4.730 & Agua & $\frac{6 \times 1 \times 2}{30,3 \times 1,3 \times 1,15}$ & & \\
\hline HU-13 & Minascocha & 9012312 & 176032 & $18 \mathrm{~S}$ & 4.710 & Agua & $12 \times 0,5 \times ?$ & & \\
\hline MA-2 & & 9007586 & 174804 & $18 \mathrm{~S}$ & 4.670 & Agua & $8 \times 1 \times 3,2$ & $\mathrm{X}$ & \\
\hline MA-3 & Mamancocha & 9006610 & 174548 & $18 \mathrm{~S}$ & 4.450 & Agua & $? \times ? \times 3$ & ¿X? & ¿X? \\
\hline MA-4 & Chaupicocha & 9006042 & 174057 & $18 \mathrm{~S}$ & 4.380 & Agua & $5,5 \times 1,3 \times ?$ & & ¿X? \\
\hline MA-5 & Quepancocha & 9005893 & 173530 & $18 \mathrm{~S}$ & 4.270 & Agua & $8,5 \times 0,8 \times 1$ & ¿X? & \\
\hline MA-10 & Saquipampa & 9013115 & 175288 & $18 \mathrm{~S}$ & 4.050 & Limo & $70 \times 2,5 \times 2$ & & $\mathrm{X}$ \\
\hline CA-6 & Ulto 1 & 9019408 & 819751 & $17 \mathrm{~S}$ & 4.380 & Limo & $12,5 \times 1,1 \times 0,8$ & & \\
\hline CA-7 & Ulto 2 & 9019330 & 819916 & $17 \mathrm{~S}$ & 4.350 & Limo & $12 \times 1,7 \times 1,2$ & & \\
\hline CA-9 & Coñocranra & 9019501 & 829023 & $17 \mathrm{~S}$ & 4.390 & Agua & $62 \times 1 \times 3$ & $\mathrm{x}$ & \\
\hline CA-10 & Tocanca & 9019368 & 171011 & $18 \mathrm{~S}$ & 4.540 & Agua & $20 \times 1 \times 1$ & $\mathrm{x}$ & \\
\hline CA-13 & Huirí & 9017187 & 829026 & $17 \mathrm{~S}$ & 4.340 & Limo & $10 \times 1 \times 1,5$ & & \\
\hline CA-15 & Huirí & 9016328 & 829845 & $17 \mathrm{~S}$ & 4.460 & Agua & $9,9 \times 2,2 \times 1$ & $\mathrm{X}$ & \\
\hline
\end{tabular}

L: Largo; An: Ancho; Al: Altura

alto de Jimbe fue el resultado de la iniciativa de una sola entidad política acomodándose a las restricciones geográficas, o más bien de distintos grupos sociales que adaptaron esta tecnología a sus necesidades? La evidencia actual establece que a partir de las características de los asentamientos tardíos identificados en la zona no se logra discernir grados de jerarquía social o política concluyentes (Lane 2010). A pesar de las escasas evidencias arqueológicas estudiadas hasta la fecha, las recientes investigaciones en el valle alto de Jimbe indican un patrón de asentamiento eminentemente disperso (Figura 17) (Gambini 1984), controlando, en mayor medida, los recursos naturales del área (Combey 2018a; Maza 2018c). De hecho, por citar un ejemplo representativo, la persistencia ocupacional del sitio arqueológico de Tzaqanan (Maza 2018c:97-122) durante varios periodos puede estar relacionado al control de las lagunas de la Quebrada Capado y a los recursos pastoriles que caracterizan esta cabecera.

\section{Conclusión}

El reconocimiento llevado a cabo en las cabeceras de las tres quebradas referidas ofrece un nuevo enfoque respecto a las estrategias de gestión del agua realizadas por las poblaciones prehispánicas y su adaptación al medio ambiente. Se puede dar cuenta, aparentemente, de como en un espacio geográficamente reducido, se identifican diferentes maneras de gestionar el recurso hídrico. Mientras que las quebradas de Huampucayán y Mátar muestran un carácter evidentemente agrícola, la Quebrada Capado se orienta más hacia una explotación pastoril, al menos, en sus partes altas. No obstante, la presencia de un extenso sistema de irrigación cuyo origen se encuentra en esta última quebrada indicaría un manejo mixto de actividades tanto pecuarias como agrícolas, esta última especialmente de los grupos ubicados en la zona quechua de los valles de Jimbe, Macate y Lacramarca.

Si bien las represas hidráulicas previamente descritas sugieren un manejo diferenciado y apuntan entonces a una función especializada, debemos precisar que no argumentamos la idea de grupos de pastores y agricultores segregados en cada una de las quebradas estudiadas. Los datos enunciados podrían revelar un modo de explotación singular de su territorio por comunidades agropastoriles (Duviols 1973; Lane 2006a). Futuros trabajos de identificación de sitios con carácter residencial en las alturas de Jimbe permitirán proveer elementos de discusión adicionales al respecto.

Aunque ningún relato etnográfico pudo ser recogido, queda claro que las represas tuvieron un impacto relevante sobre las poblaciones que las construyeron, asícomo sobre 


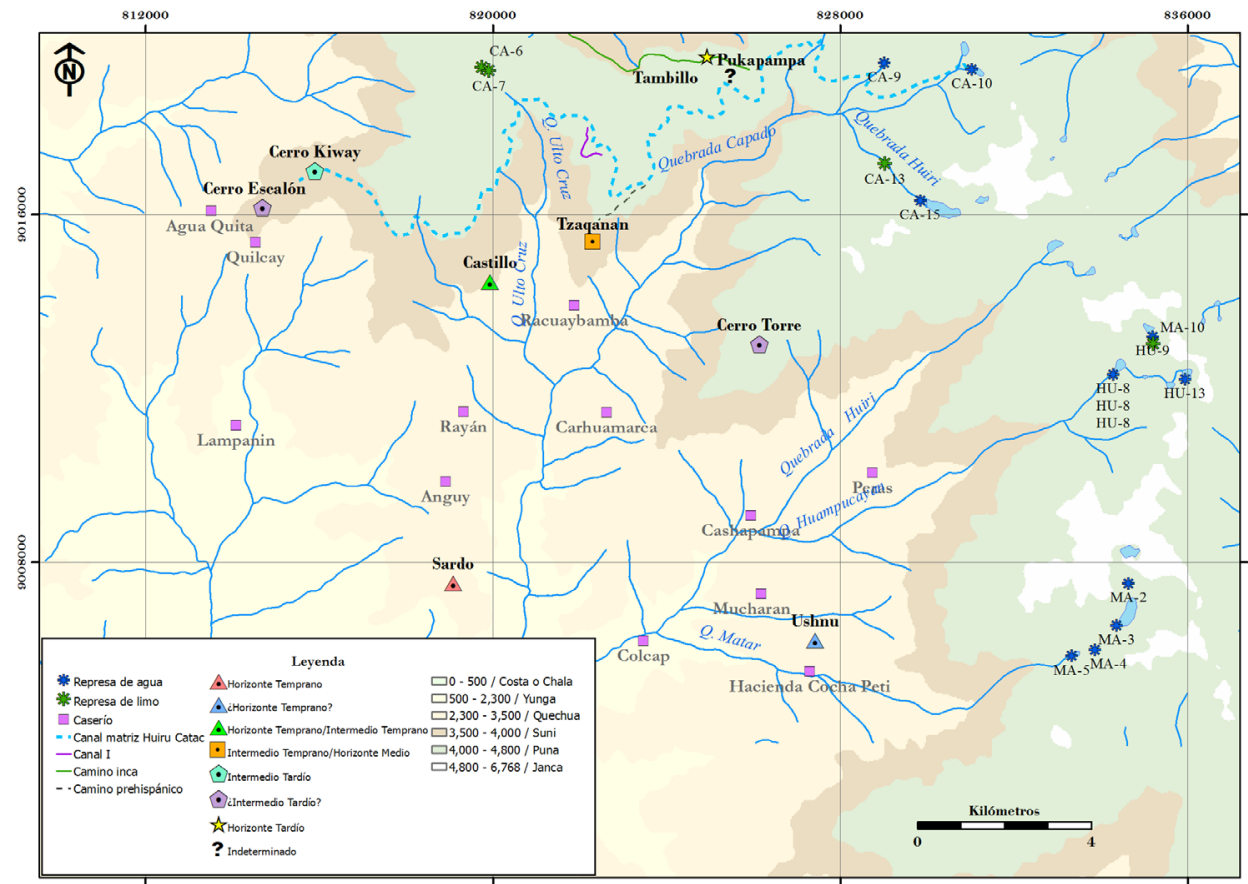

Figura 17. Mapa de ubicación de sitios arqueológicos y obras hidráulicas identificadas durante la prospección. Mapa realizado por Jesús Maza.

Location map of archaeological sites and identified hydraulic works. Map by Jesús Maza.

las que vivían río abajo, en la región quechua y yunga. La primera, fue una región natural de suma relevancia para el cultivo del maíz (Zea mays), mientras que la segunda lo era para la coca (Erythroxylum coca) en épocas prehispánicas (Rostworowski 1973). La situación actual entre los caseríos de Peras y Mucharán en la Quebrada de Huampucayán, así como datos en otras regiones durante la época prehispánica (Ávila 1966 [1598]; Rostworowski 1988), demuestra que diversas tensiones y conflictos pudieron nacer del manejo y repartición del agua. Estos acontecimientos coyunturales crearon, sin duda, ciertos escenarios de disputa por la apropiación de los recursos hídricos y, además, permitieron afianzar los lazos comunales de cooperación, reflejados claramente en este tipo de obras hidráulicas (Chacaltana y Cogorno 2018).

El control de las bocatomas y, de manera general, de los recursos hídricos especialmente artificiales, proporcionaba un poder político, económico y simbólico muy importante en la época prehispánica (Glowacki y Malpass 2003; Gose 1993; Sherbondy 1982). Las poblaciones que ocuparon las cabeceras de las quebradas de Jimbe controlaban una fuente de agua sustancial e indispensable para el mantenimiento de las actividades agrícolas en las partes baja y media del Valle de Nepeña. La sucesión de demandas legales contra la poderosa hacienda de Jimbe entre los siglos XVII y XIX constituyen probablemente un vestigio de las tentativas de acaparar los recursos hídricos de las poblaciones altoandinas de Jimbe (Muñoz 2002; Thurner 1997:86), además de referencias más modernas halladas en fuentes documentales locales (Portugal 1983).

La investigación arqueológica que estudie este tipo de obras hidráulicas en los Andes aún se encuentra en un estado incipiente. Mayores apreciaciones tecnológicas y constructivas pueden realizarse a partir de la ciencia hidráulica para conocer y precisar las características que permiten que estas obras se mantengan, de manera general, casi intactas a través del tiempo y en uso por las comunidades altoandinas actuales.

Agradecimientos: Nuestro profundo agradecimiento a las comunidades altoandinas de Peras, Cochapetí y Anguy, quienes nos proporcionaron información sustancial para desarrollar la presente investigación. A Romel Garay, Marcela Sepúlveda y Jorge Gamboa, cuyas críticas y comentarios contribuyeron a mejorar la calidad del artículo. Finalmente, a los revisores externos por sus valiosas sugerencias y críticas al manuscrito. Como siempre, cualquier error será enteramente de los autores. 


\section{Referencias Citadas}

Albeck, M. E. 2011. Estudios sobre agricultura prehispánica en Casabindo (1980-1993). En Arqueología de la Agricultura. Casos de Estudio en la Región Andina Argentina, editado por M. A. Korstanje y M. N. Quesada, pp. 12-47. Ediciones Magna, San Miguel de Tucumán.

Antúnez de Mayolo, S. 1986. El riego en Aija. Allpanchis 18 (28):47-71.

Arguedas, J.M. 1956. Puquio, una cultura en proceso de cambio. Revista del Museo Nacional 25:184-232.

Ávila, F. 1966 [1598]. Dioses y Hombres de Huarochiri; Narración Quechua Recogida por Francisco de Ávila [i1598?]. Traducido por J. Arguedas. Instituto de Estudios Peruanos, Lima.

Arriaga, P.J. 1621. Extirpacion de la Idolatria del Piru.: Dirigido al Rey N.S. en su Real Conseio de Indias. Por Geronymo de Contreras impressor de libros, Lima. Recuperado de: https://archive.org/ details/extirpaciondelai00arri/page/n5 (12 diciembre 2019)

Aspíllaga Delgado, A. 1953. Rocro y Palacio Colcap. Ruinas ocultas en la Cordillera. El Comercio, Agosto 24, Lima.

Berrocal, M. 2014. Lagunas: Espacios sagrados y sistemas hidráulicos prehispánicos. Alteritas. Revista de Estudios Socioculturales Andino Amazónicos 3:121-148.

Boelens, R. 2014. Cultural politics and the hydrosocial cycle: Water, power and identity in the Andean highlands. Geoforum 57:234-247.

Carlier, A. 2008. Le nettoyage rituel des canaux d'irrigation d'une communauté de la cordillère de Lima (province de Canta, Pérou): une approche ethnohistorique. Bulletin de l'Institut Français d'études Andines 37 (2):351-374.

Carrión Cachot, R. 2005 [1955]. El Culto al Agua en el Antiguo Perú. Instituto Nacional de Cultura, Lima.

Chacaltana S. y G. Cogorno 2018. Arqueología Hidráulica Prehispánica del Valle Bajo del Rímac (Lima, Perú): Estudio de un Sistema de Riego Costeño. Instituto Riva-Agüero, Pontificia Universidad Católica del Perú, Lima.

Combey, A. 2018a. Dynamiques Spatiales et Mobilités dans la Cordillère Noire: Permanences et Evolutions. Tesis de maestría en Arqueología andina. Université Paris 1 Pantheón Sorbone, Paris.

Combey, A. 2018b. Lagunas y antiguas represas en las alturas de Jimbe, distrito Cáceres del Perú. Revista Sedir 2:36-37.

Consejo Andino de Manejo Ecológico 1988. Agua y Agricultura Andina. Lima

Contreras, D. 2010. Landscape and Environment: Insights from the Prehispanic Central Andes. Journal of Archaeological Research 18:241-288

Custred, G. 1977. Las punas de los Andes Centrales. En Pastores de Puna: Uywamichiq Punarunakuna, editado por J. Flores, pp.55-85. Instituto de Estudios Peruanos, Lima.

Doughty, P. 1970. Huaylas: Un Distrito Andino en pos de Progreso. Instituto Indigenista Interamericano, México DF.

Duviols, P. 1973. Huari y Llacuaz Revista del Museo Nacional 39:153-191.

Estete, M. 1891 [1534]. La relación del viaje que hizo el señor capitán Hernando Pizarro por mandado del señor gobernador, su hermano, desde el pueblo de Caxamalca á Parcama, y de allí á Jauja. En Verdadera Relación de la Conquista del Perú, editado por F. De Xerez, pp. 121-149. Madrid.

Farfán, C. 2002. El simbolismo en torno al agua en la comunidad de Huaros-Canta. Bulletin de l'Institut Français d'Études Andines 31 (1):115-142.
Fauré, F. y F. Peña 1999. Informe de la Visita a las Lagunas y Represas de la Cordillera Negra. Junta de Desarrollo Distrital de Moro, Moro.

Gambini, W.E. 1975. Monografía de Cáceres del Perú (distrito de la provincia del Santa, dpto. De Ancash). Edición del autor, Lima.

Gambini, W.E. 1984. Santa y Nepeña. Dos Valles. Dos Culturas. Edición del autor, Lima.

Garcilaso, I. 1918 [1609]. Los Comentarios Reales de los Incas. Imprenta y Librería Sanmarti y Ca., Lima.

Gelles, P. 1986. Sociedades Hidráulicas en los Andes: Algunas perspectivas desde Huarochirí. Allpanchis 18 (27):99-147.

Gelles, P. 2002. Agua y Poder en la Sierra Peruana: la Historia y Política Cultural del Riego, Rito y Desarrollo. Fondo Editorial Pontificia Universidad Católica, Lima.

Gerbrandy, G. y P. Hoogendam 1998. Agua y Acequias: Los Derechos al Agua y la Gestión Campesina de Riego en los Andes Bolivianos. Plural Editores, Cochabamba.

Glowacki, M. y M. Malpass 2003. Water, huacas, and ancestor worship: Traces of a sacred Wari Landscape. Latin American Antiquity 14 (4):431-448.

Gonzales, D. 2018. Yakupa qorin. Memoria y vigencia de los relatos sobre lagunas en los Andes norcentrales. Revista UNASAM 1 (2):99-106.

Gose. P. 1993. Segmentary state formation and the ritual control of water in the Incas. Comparative Studies in Society and History 35 (3):480-514

Greslou F. 1988. Consideraciones sobre el agua en la agricultura andina. En Agua y Agricultura Andina, pp. 29-40. CAME, Proyecto de Tecnologías Campesinas, Lima.

Grillo, E. 1994. El paisaje en las culturas andinas y occidental moderna. En Crianza Andina de la Chacra, editado por E. Grillo, G. Rengilfo, J. Valladolid y V. Quispe, pp. 9-45. Proyecto Andino de Tecnologías Campesinas, Lima.

Hernández Príncipe, R. 1923. Mitología Andina. Revista Inca 1 (1):25-68.

Huaman Poma de Ayala, F. 2017 [1613]. Nueva Crónica y Buen Gobierno, editado por C. Araníbar. Biblioteca Nacional del Perú. Ministerio de Relaciones Exteriores del Perú, Lima.

Kosok, P. 1965. Life, Land and Water in Ancient Peru. Long Island University Press, New York.

Lane, K. 2006a. Engineering the Puna: The Hydraulics of AgroPastoral Communities in a North-Central Peruvian Valley. Tesis doctoral. University of Cambridge, Archaeology, Cambridge.

Lane, K. 2006b. Through the looking glass: Re-assessing the role of agro-pastoralism in the North-Central Andean Highlands. World Archaeology 38 (3):493-510.

Lane, K. 2010. Continuidad y cambio en comunidades Huaylas durante el periodo Intermedio, Inka y Colonial 1000-1615 d.C. Inka Llaqta 1:7-28

Lane, K. 2011. Hincapié en los Andes nor-centrales: la presencia inca en la Cordillera Negra, sierra de Ancash. En Arquitectura Prehispánica Tardía: Construcción y Poder en los Andes Centrales, editado por K. Lane y M.L. Dávila, pp. 123-170. Universidad Católica Sedes Sapientiae, Lima.

Lane, K. 2016. Water technology in the Andes. En Encyclopaedia of the History of Science, Technology, and Medicine in NonWestern Cultures, editado H. Selin, pp.1-24. Springer, Dordrecht.

Lane, K. y J. Grant 2016. A Question of Altitude. Exploring the Limits of Highland Pastoralism in the Prehispanic Andes. En The Archaeology of Andean Pastoralism, editado por J.M. Capriles 
y N. Tripcevich, pp. 139-157. University of New Mexico Press, Albuquerque.

Lanzelotti, S. 2011. Indicadores para el reconocimiento de represas arqueológicas. Relaciones de la Sociedad Argentina de Antropología 36:177-196.

Llosa, J. 2008. Informe Técnico. Elaboración e Implementación de un Programa Nacional de Adaptación al Cambio Climático, con énfasis en zonas seleccionadas de la Sierra Centro y Sur del País. CONCYTEC, Lima.

Matos, S. 2000. Huaylas y Conchucos en la Historia Regional. Editorial San Marcos, Lima.

Maza, J. 2018a. Un caso de ingeniería hidráulica prehispánica en la cuenca alta del valle de Nepeña, el sistema de irrigación Huiru Catac. In Crescendo 9 (1):133-162.

Maza, J. 2018b. El agua de los ancestros: algunas notas sobre el sistema de riego prehispánico Huiru Catac. Actas del I Coloquio de Arqueología del Museo de Sitio Julio C. Tello de Paracas, pp. 92115. Ministerio de Cultura, Dirección Desconcentrada Ica, Lima.

Maza, J. 2018c. El Riego en las Tierras Altas: Aproximaciones a partir del Estudio Arqueológico del Sistema Hidráulico Huiru Catac, Cuenca Alta de Nepeña. Tesis de Licenciatura. Universidad Nacional Mayor de San Marcos, Lima.

Mitchell, W. 1981. La agricultura de riego en la sierra central de los Andes: implicaciones para el desarrollo del estado. En La Tecnología en el Mundo Andino, editado por H. Lechtman y A.M. Soldi, pp.135167. Universidad Nacional Autónoma de México, México DF.

Mogrovejo, T. 1920. Diario de la segunda visita pastoral del Arzobispo Toribio Alfonso de Mogrovejo. Revista del Archivo Histórico Nacional del Perú, Tomo I - Entrega I:49-81.

Muñoz, L. 2002. La Cuenca del Nepeña y el Puerto de Chimbote. Edición del autor, Lima.

Murra, J. 2002a. El control vertical de un máximo de pisos ecológicos en la economía de las sociedades andinas. En El Mundo Andino, pp. 85-125. Instituto de Estudios Peruanos, Pontificia Universidad Católica del Perú-Fondo Editorial, Lima.

Murra, J. 2002b. La función del tejido en varios contextos sociales y políticos. En El Mundo Andino, pp. 153-170. Instituto de Estudios Peruanos, Pontificia Universidad Católica del PerúFondo Editorial, Lima.

Ortloff, C. 1981. La ingeniería hidráulica Chimú. En La Tecnología en el Mundo Andino, editado por H. Lechtman y A. M. Soldi, pp. 91-134. Universidad Nacional Autónoma de México, México DF.

Ortloff, C. y M. Moseley 2009. Climate, agricultural strategies, and sustainability in the Precolumbian Andes. Andean Past 9:277-304.

Osorio, A. y C. Santoro 1989. Trasvase prehispánico VilasamaniSocoroma, norte de Chile. Idesia 11:37-43.

Ossio, J. 1978. El simbolismo del agua y la representación del tiempo y el espacio en la fiesta de la acequia de la comunidad de Andamarca. Actes du XLII Congrès International des Américanistes, pp. 377-396. Société des Américanistes, Paris.

PACC PERU 2014. Las Qochas Rústicas, una Alternativa en los Andes para la Siembra y Cosecha de Agua en un Contexto de Cambio Climático. Programa de Adaptación al Cambio Climático - PACC Perú, Lima.

Palacios, F. 1977. Pastizales de regadío para Alpacas. En Pastores de Puna: Uywamichiq Punarunakuna, editado por J. Flores, pp. 155-170. Instituto de Estudios Peruanos, Lima.
Parcero-Oubiña, C., P. Fábrega-Álvarez, A. Troncoso, D. Salazár, F. Hayashida, C. Borie y M. Pino 2016. Sistemas agrohidráulicos en el Loa Superior: el caso de Topaín. Boletín de la Sociedad Chilena de Arqueología 46:23-42.

Portugal, J. 1983. Eslabones de una Cadena Llamada Chimbote. Consultoría de Proyectos Agroindustriales, Lima.

Pulgar Vidal, J. 1998. Las Ocho Regiones Naturales del Perú. Peisa, Lima.

Raimondi, A. 1873. El Departamento de Ancachs y sus Riquezas Minerales. El Nacional, Lima.

Rostworowski, M. 1973. Plantaciones prehispánicas de coca en la vertiente del Pacífico. Revista del Museo Nacional 39:193-224.

Rostworowski, M. 1988. Conflicts over Coca Fields in XVIth-Century Peru. University of Michigan Press, Museum of Anthropology, Ann Arbor.

Rostworowski, M. 2006. Sistemas hidráulicos de los señoríos costeños prehispánicos. En Ensayos de Historia Andina II: Pampas de Nasca, Género, Hechicería, Editador por pp. 125149. Instituto de Estudios Peruanos, Lima.

Salomon, F. 1998. Collquiri's Dam: The Colonial Re-Voicing of an Appeal to the Archaic. En Native Traditions in the Postconquest World, editado por E. Hill Boone y T. Cummins, pp. 265-294. Dumbarton Oaks Research Library and Collection, Washington D.C.

Samaniego, L. 1991. Informe de Expedición a Represas, Lagunas y Zonas Arqueológicas de Pamparomás y Moro, región Chavín. Informe de campo, Casma.

Sancho, P. 1917. Relación para SM de lo sucedido en la conquista y pacificación de estas provincias de la Nueva Castilla. En Las Relaciones de la Conquista del Perú, editado por H.H. Urteaga, pp. 124-202. Imprenta y Librería Sanmarti y Ca., Lima

Schaedel, R.P. 1985. Coast-Highland Interrelationships and Ethnic Groups in Northern Peru (500 B.C.-A.D. 1980). En Andean Ecology and Civilization. An Interdisciplinary Perspective on Andean Ecological Complementarity, editado por S. Masuda, I. Shimada y C. Morris, pp. 443-474. University of Tokyo Press, Tokio.

Sherbondy, J. 1982. El regadío, los lagos y los mitos de origen. Allpanchis 14 (20):3-32.

Tello, J. y P. Miranda 1923. Wallallo: Ceremonias gentilicias realizadas en la Región Cisandina del Perú Central. Revista Inca I:474-549.

Thurner, M. 1997. From Two Republics to One Divided: Contradictions of Postcolonial Nationmaking in Andean Peru. Duke University Press, Durham, Londres.

Valderrama, R. y C. Escalante 1988. Del Tata Mallku a la Mamapacha. Riego, Sociedad y Ritos en los Andes Peruanos. DESCO, Lima.

Varón, R. 1980. Curacas y Encomenderos: Acomodamiento Nativo en Huaraz, Siglos XVI y XVII. P.L. Villanueva, Lima.

Villafana, J. 1986. Sistemas Hidráulicos Incas. Lluvia Editores, Lima.

Vivanco, C. 2015. Obras hidráulicas de etapa prehispánica en Huaccana, Chincheros-Apurímac. Arqueología y Sociedad 30:315-333.

Zuloaga, M. 2012. La Conquista Negociada: Guarangas, Autoridades Locales e Imperio en Huaylas, Perú (1532-1610). Institut Français d'Études Andines, Lima. 


\section{Notas}

${ }^{1}$ El sistema hidráulico Huiru Catac es una extensa red de riego, cuyo canal principal se originaba probablemente en la Laguna Coñocranra, aunque Gambini indica que su fuente inicial estuvo en la Laguna Tocanca. Estuvo compuesto de un canal matriz, de $29 \mathrm{~km}$ aproximadamente, y de tres canales o conductos secundarios; estos últimos ramales, específicamente el CS-1 y el CS-3, permitieron trasvasar el agua hacia las cuencas del Río Kiway (Macate) y Lacramarca, respectivamente. Como ha sido descrito en un detallado trabajo (Maza 2018c), el canal madre se borra en inmediaciones del sitio arqueológico Cerro Kiway, por lo que se ha propuesto que tuvo como finalidad irrigar las zonas quechuas debajo de este sitio arqueológico, el cual presenta una ocupación del periodo Intermedio Tardío a partir de los indicadores arqueológicos observados. De acuerdo a la evidencia asociada, se ha sugerido que la construcción de este sistema pudo iniciarse a fines del periodo Horizonte Medio o inicios del periodo Intermedio Tardío. No se descarta que, considerando que el canal madre cruza extensos pastizales naturales y cabeceras de quebrada, parte del fluido pudo haber sido utilizado para potenciar actividades agropastoriles en la puna (Maza 2018c).
${ }^{2}$ Información otorgada según la carta geológica Corongo 18-h (escala 1:100 000).

${ }^{3}$ Consultado en http://geocatmin.ingemmet.gob.pe/geocatmin/ (12 diciembre 2019)

${ }^{4}$ Hasta el 2009 existían alpacas en algunas comunidades altoandinas de Jimbe (Carhuamarca especialmente). Estos eran los últimos ejemplares sobrevivientes de un grupo de 300 ejemplares traído de regiones sureñas unos años atrás. Los camélidos pastaban principalmente en las cabeceras de la Quebrada Capado (Edmundo Paz, comunicación personal 2019).

${ }^{5}$ Designada por él como Juan-Pucallan.

${ }^{6}$ Una referencia hacia este paso natural se encuentra, también, en la obra de un historiador regional (Matos 2000), quien afirma, sin precisar base documental alguna, que fue por esta quebrada por donde cruzaron la cordillera las huestes incaicas al mando del general Asto Huaraca en la campaña militar para sojuzgar a los pueblos de la región de Huaylas. ${ }^{7}$ Lloqlla es el término quechua que alude a lo que comúnmente se conoce como huaycos (Parker y Chávez 1976:94).

${ }^{8}$ Se observó un canal antiguo en la ladera este de la Quebrada Mátar, y ubicado arriba de la acequia actual. 